\title{
Auch wir sind in Arkadien geboren
}

\author{
Freundschaftswidmungen von Hölderlin und Hegel \\ in einem unbekannten Stammbuch
}

Von Stefan J. Dietrich

\section{Einleitung}

In einem seiner Beiträge zu neu entdeckten Stammbuchlättern Hölderlins und Hegels hat Volker Schäfer aus der Erkenntnis, dass deren Freundeskreis größer war als bisher gesehen, die Hoffnung auf neues Quellenmaterial geschöpft ${ }^{1}-\mathrm{zu}$ Recht. In einem badischen Auktionshaus wurde Ende 2012 ein als „Poesiealbum“ deklariertes Stammbuch versteigert, in dem sich Einträge von Hölderlin und Hegel fanden. Dieses Album amicorum ${ }^{2}$, Gönnern, Freundinnen und Freunden gewidmet von Christian Amandus Heinrich Dobel, der Arznei-Gelartheit Candidat, von RommelsPach aus dem Würtembergischen im Jar 1789 (Abb.2), enthält auf 202 unpaginierten Seiten 199 Einträge ohne Register, darunter 144 aus Tübingen, die von Januar 1789 bis März 1792 datieren. Eine kleine, fast noch kindlich anmutende Silhouette des Besitzers schmückt das Frontispiz (Abb. 1) ${ }^{3}$.

1 Volker SchäFer, Neue Stammbuchblätter von Hölderlin und Hegel, in: In Wahrheit und Freiheit. 450 Jahre Evangelisches Stift in Tübingen, hg. von Friedrich Hertel (Quellen und Forschungen zur württembergischen Kirchengeschichte, Bd. 8), Stuttgart 1986, S. 177204, hier S. 204; auch in: Ders., Aus dem Brunnen des Lebens. Gesammelte Beiträge zur Geschichte der Universität Tübingen, Festgabe zum 70. Geburtstag, hg. von Sönke Lorenz/ Wilfried Setzler (Tübinger Beiträge zur Landesgeschichte, Bd. 5), Ostfildern 2005, S. $300-$ 324, hier S. 324. Vgl. auch Adolf BECK, Aus der Umwelt des jungen Hölderlin. Stamm- und Tagebucheinträge, in: Hölderlin-Jahrbuch 2 (1947) S. 18-46, hier S. 40. - Erst im Mai 2011 erwarb die Württembergische Landesbibliothek bei einer Hamburger Auktion das Stammbuch von Johann Gottfried Carl Merian mit der bis dato frühesten Freundschaftswidmung Hölderlins (vgl. Anm. 46).

${ }^{2}$ Queroktav (11,4 x 16,5 x 2,2 cm), Vollleder mit reicher Rückenvergoldung und reicher Goldbordüre über drei Bünden, Goldschnitt, Wasserzeichen JHONIG \& ZONEN mit Krone und Bienenkorb (vier Stege im Abstand von 2,55 cm), im originalen mit Buntpapier ausgeschlagenen Pappschuber (11,7 x 18 x 2,6 cm), Privatbesitz.

${ }^{3}$ Der getuschte Schattenriss misst nur ca. 3 x 2,2 cm, das eingeklebte Trägerblättchen $9 \times$ $6,5 \mathrm{~cm}$. Zwar haben lediglich drei Einträger ihre Silhouetten beigefügt (Stammbuch (künftig: 


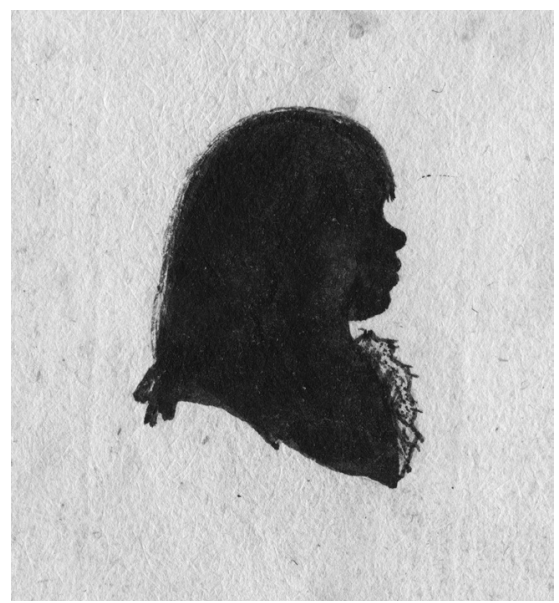

Abb. 1

\section{Der Stammbuchhalter}

Christian Amandus Heinrich Dobel erblickte am 25. Januar 1770 in Rommelsbach, heute ein Stadtteil von Reutlingen, als viertes Kind des dortigen Pfarrers Amandus Valentin Dobel (1730-1801) und der Charlotta Sophia geb. Müllner (1734-1793) das Licht der Welt. Der Vater, der anderntags die Taufe vornahm, schon Pfarrerssohn, stammte aus Holzmaden, die Mutter war die Tochter eines Fürstlich-Bayreuthischen Justizrats zu Hof ${ }^{4}$. Mit fünf Geschwistern wuchs Chris-

Stb.) Dobel Nr. 13, 63, 132), doch sind ihrer 46 in den elf noch greifbaren Stammbüchern von Freunden Dobels nachweisbar, davon allein 26 im Album von Christian Friedrich Hiller (wie Anm. 40).

4 Taufregister Rommelsbach, Landeskirchliches Archiv Stuttgart KB 1910, Bd. 2; Familienregister Rommelsbach, ebd., KB 1911, Bd. 10, S. 41 (freundliche Auskunft von Frau Birgitta Häberer); vgl. auch: Die Württembergischen Familienstiftungen, hg. von Ferdinand Friedrich Faber, 20. Heft, Stuttgart 1857, Neudruck mit Berichtigungen von Adolf ReNTSCHLER, Stuttgart 1940, LXXXV (Varenbühler-Grüninger-Hiller) C \$114; Das evangelische Württemberg, bearb. von Christian SigeL, Teil 2, Generalmagisterbuch, Bd. 11, Bl. 834; Ortsfamilienbuch der württembergischen, bis zum 30.06.1974 selbständigen Gemeinde Rommelsbach 1639 bis ca. 1910, bearb. von Helmut Tнuмм, Deutsche Ortssippenbücher, Reihe A, Bd.372 (Württembergische Ortssippenbücher, Bd.70), Rommelsbach 2004, Nr.136-137, S. 29f., Nr.1354, S. 287. - Die Großeltern mütterlicherseits waren Johann Carl Sigmund Müllner (1698-1763) von Voigtsberg bei Oelsnitz, Justizrat zu Hof, und Ursula Magdalena geb. Oheim (1695- nach 1764) von Hof; vgl. auch Anm. 30. Vor der Übernahme des Pfarramtes in Rommelsbach 1763 diente Amandus Valentin Dobel vier Jahre als Feldprediger beim Infanterie-Regiment Baden-Baden (BWKG 1905, S. 83 und 1906, S.130). Nach einer Rommelsbacher Chronik sei er ein häuslicher Mensch gewesen und habe bei mittelmäßigen Studien sein Amt stets treu verrichtet (vgl. Thum (wie oben) S. 29). Am 27. Novem- 


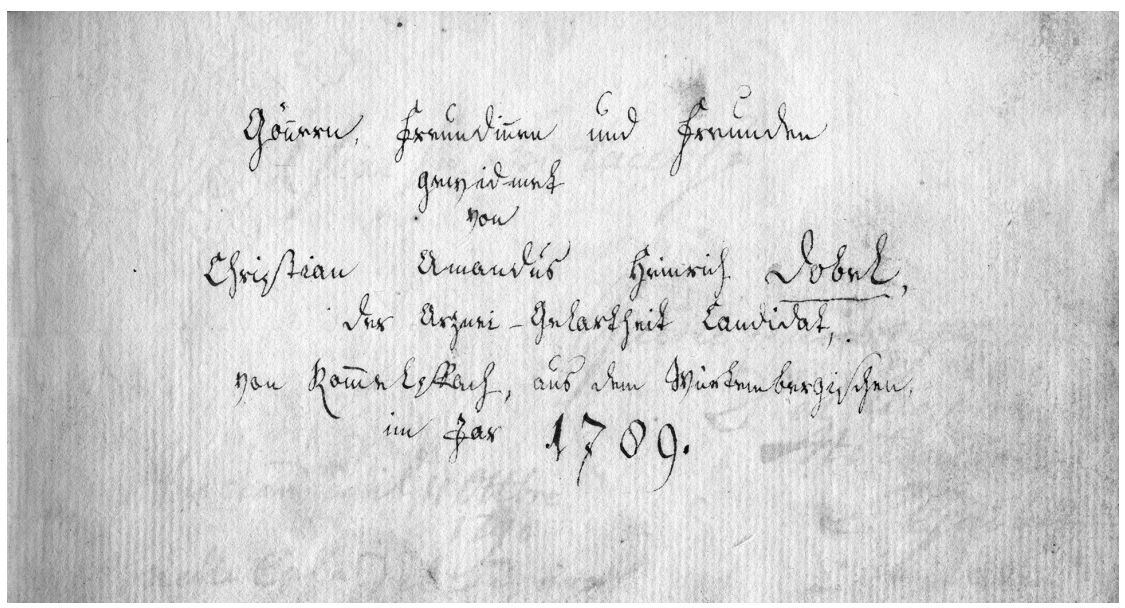

Abb. 2

tian, wie der Rufname lautete, auf ${ }^{5}$. Noch keine 17 Jahre alt immatrikulierte er sich am 27. Oktober 1786 an der Universität Tübingen für das Studium der Medizin $^{6}$. Dobel hatte das Glück, im November des folgenden Jahres durch Herzog Carl

ber 1753 trug er sich in das Stammbuch von Christoph Ludwig Mieg (1731-1807) ein, der 1788 Hölderlins Prälat in Maulbronn wurde (Universitätsbibliothek Tübingen Mh 1041, Bl. 287, online gestellt).

${ }^{5}$ Johann Friedrich (1764-1819), Feldprediger beim Kürassier-Regiment Hohenzollern 1794 (BWKG 1906, S. 135), 1798 Diakonus, 1807 Pfarrer in Metzingen (Stb. Dobel Nr. 133); Magdalena Charlotte (1766-1829, Stb. Dobel Nr. 67), verehelicht 1795 mit Johann Christian Heinrich Schmid (1761-1832), Ritterschaftlicher Registrator in Tübingen, zuletzt Rechnungsrat in Stuttgart; Jakobine Friederike (1767-1851), ledig, in Metzingen (Stb. Dobel Nr. 69); Carl Emanuel (1771-1837), Registrator in Karlsruhe; Carl August (1774- nach1829), Conditor in Stuttgart, dessen Zwillingsbruder Constantin Valentin nur zwei Monate lebte (vgl. Anm.4). Von den fünf Taufpaten Dobels waren drei Pfarrer, namengebend Christian Hagen (1698-1776) von Bayreuth, seit 1729 amtierend in Köditz bei Hof, vermutlich ein Verwandter der Mutter (vgl. Gelehrtes Fürstenthum Baireut, hg. von Georg Wolfgang Augustin Fikenscher, Bd. 4, Erlangen 1801, S. 187); der dritte Vorname wohl nach dem Großvater, Valentin Heinrich Dobel (1685-1755) von Adelberg, Sohn eines Forstverwalters, seit 1726 Pfarrer in Holzmaden (vgl. Anm. 4). Die Konfirmation erfolgte auf Quasimodogenitis am 18. April 1784 durch den Vater (Konfirmationsregister Rommelsbach, Landeskirchliches Archiv Stuttgart KB 1910, Bd.8, S. 5). Die ältere Schwester beerdigte Nathanael Friedrich Köstlin (1776-1855), Sohn von Hölderlins Nürtinger Lehrer Nathanael Köstlin (1744-1826) und Cousin Schellings. Vgl. Ders., Rede am Grabe der Frau Magdalene Charlotte Schmid geb. Dobel, Stuttgart 1829; vgl. auch Anm. 23, 44, 71.

${ }^{6}$ Die Matrikeln der Universität Tübingen, Bd.3, 1710-1817, bearb. von Albert BüRK/ Wilhelm Wille, Tübingen 1953 (künftig: MUT), Nr. 38516. Damit trat er in die Fußstapfen seines kinderlosen Onkels Dr. med. Matthäus Friedrich Dobel (1728-1783) in Beihingen am Neckar (MUT, Nr. 34631), dessen erste Gattin seine Patentante war (vgl. Anm. 4). Die Konkurrenz der Hohen Karlsschule in Stuttgart hatte die Zahl der Einschreibungen für Medizin 
Eugen auf drei Jahre zum Hospitum-Tisch (Freitisch) des Evangelischen Stifts zugelassen zu werden, wo er viele neue Freunde fand ${ }^{7}$. Er trat einem der damals verbreiteten geheimen Studentenorden bei und scheint Sympathien für die Französische Revolution gehegt zu haben ${ }^{8}$. Sein Studium schloss er im Sommersemester

in Tübingen stark reduziert: 1784 waren es elf, 1785 fünf, 1786 nur drei (mit Dobel), 1787 sechs, 1788 acht, 1789 und 1790 sechs. Vgl. MUT, S.319-343. So erklärt sich, dass nur 15 Tübinger Medizinstudenten in Dobels Stammbuch zu finden sind.

7 Einer der beiden Plätze für Medizinstudenten war vorzeitig frei geworden. Gegen den Mitbewerber Johann Heinrich Roth (1764-1791) von Herrenberg (Stb. Dobel Nr. 89) scheinen die günstigen Beiberichte des Tübinger Dekans Ernst Bengel (1735-1793) den Ausschlag gegeben zu haben, worinnen bestätiget wird, daß der Vatter dieses jungen Dobels es sich sehr sauer werden lasse, seine 4 Söhne jeden etwas anständiges erlernen zu lassen; Bericht des Kirchenrats an den Herzog vom 15. November 1787, HStA Stuttgart A 284/95, Bü 122a, Nr. 44/18. Im Stift traf Dobel noch seinen älteren Bruder Johann Friedrich an, der 1783 als Bebenhauser „Klosterschüler“ eingerückt war - wie schon der Vater und der Großvater (vgl. MUT, Nr. 29617, 34600, 38059; BWKG 1977, S. 41, 51 und 1980/81, S. 47, 67). Von den 92 Theologiestudenten, die ihre Freundschaft in Dobels Album bekundeten, sind 68 Stiftler und zwei Hospites - die Stiftsjahrgänge 1784 bis 1790 umfassen rund 200 Personen. Hölderlins und Hegels Promotion von 1788 bestand aus 35 Studenten, von welchen 23 im Stammbuch Dobel vertreten sind, darunter die vier Mömpelgarder. Vgl. MUT, S. 319-351; Priscilla A. Hayden-Roy, „Sparta et Martha“. Pfarramt und Heirat in der Lebensplanung Hölderlins und in seinem Umfeld (Tübinger Bausteine zur Landesgeschichte, Bd.17), Ostfildern 2011, S. 323-344. Wie das sogenannte "Carentgatter" ausweist, ein Verzeichnis von Verstößen gegen die Stiftsordnung, die in leichteren Fällen mit Entzug, „Carition“, des Tischweins bestraft wurden, war Dobel diszipliniarisch unauffällig und auch nie im Karzer (freundliche Auskunft von Frau Beate Martin, Stiftsarchiv Tübingen). Vgl. hierzu Martin BRecht, Hölderlin und das Tübinger Stift 1788-1793, in: Hölderlin-Jahrbuch 18 (1973/74) S. 20-48, hier S. 32-34.

${ }^{8}$ Von den Stammbucheinträgern unterzeichnen 33 mit Freund und Bruder, man liest Schwarz Brod und Freiheit!, stößt auf das Kürzel des verbotenen C.V.P.V.-Ordens, das Harmonistenzeichen, eine Buchstabenfolge der Amicisten und gekreuzte Degen (Stb. Dobel Nr. 2, 3, 18, 19, 29, 68, 81, 176). Am 1. und 2. Oktober 1790 trafen sich Dobel und einige Kommilitonen, darunter der Hölderlinfreund Christian Ludwig Bilfinger (vgl. Anm. 39), mit Karlsschülern im Gasthaus „Zum Schwarzen Adler“ am Stuttgarter Marktplatz, ein Treffpunkt der Revolutionsbegeisterten, wo auch der Publizist Christian Friedrich Daniel Schubart ein- und ausging (Stb. Dobel Nr. 2-5, 14, 19, 108, 199). Am 11. Oktober kam man bei Vater Stauch zusammen - ein Christian Stauch war Musikmeister an der Karlsschule (Stb. Dobel Nr. 1, 82, 97; HStA Stuttgart A 272, Bü 133). Dass es eine Verbindung zwischen Tübinger und Stuttgarter Studenten gab, dokumentiert der Eintrag des Karlsschülers Johann Friedrich Schäffer (1772-1800), gestorben als Stadtphysicus in Ulm, datiert den 10. Oktober 1790 im Bruderkreise (Stb. Dobel Nr. 33; vgl. Werner Gebhardt, Die Schüler der Hohen Karlsschule. Ein biographisches Lexikon, Stuttgart 2011, S. 457). Zwei Tage später fügte Ernst Carl Wilhelm Le Bret, Kaufmannslehrling bei Schiele \& Liesching in Stuttgart, Sohn des Tübinger Universitätskanzlers, seinem Widmungstext das Symbolum hinzu Dort herrschen keine Vorurtheile mehr (Stb. Dobel Nr. 166; vgl. Anm. 59). Vgl. Georg Schmidgald, Tübinger Studenten im Zeitalter der Orden und Landsmannschaften 1770-1815, in: Tübinger Blätter 14 (1912) S. 20-25; Ders., Die akademischen Logen und Studentenorden in Tübingen, in: Beiträge zur Tübinger Studentengeschichte, Bd.3, Tübingen 1939/49, S. 97-122; Axel Kunn, Revolutionsbegeisterung an der Hohen Carlsschule. Ein Bericht, Stuttgart-Bad

Zeitschrift für Württembergische Landesgeschichte 74 (2015), S. 99-119.

(C) Kommission für geschichtliche Landeskunde in Baden-Württemberg und Württembergischer Geschichts- und Altertumsverein e.V.

ISSN 0044-3786 
1790 mit der Dissertation „de myositide et neuritide praesertim rheumatica per historiam agrae illustrata "9 ${ }^{\text {" }}$ unter Professor Wilhelm Gottfried Ploucquet (17441814) ab. Deren Inhalt fasst das „Repertorium der medicinischen Litteratur“ wie folgt zusammen: „Eine 30jährige Frau hatte ein Gliederreissen, das ungeachtet der angewandten Mittel langwierig und so lang anhaltend war, bis das verdorbne Zahnfleisch einigen Verdacht von Schaarboksschärfe erregte, die auch durch den Gebrauch antiscorbutischer Mittel vorzüglich Kressigs ${ }^{10}$ mit bitteren Extracten vollkommen gehoben wurde. Es folgt nun ein weitläufiger Commentar, und eine Ploucquetsche nosologische Eintheilung des Rheumatismus. "11 Darauf erhielt Dobel im September 1790 den akademischen Grad eines Lizenziaten der Medizin, dem Doktor so gut wie gleichgestellt, aber weniger kostspielig ${ }^{12}$. Ende Oktober verließ er seine Alma mater und ließ sich spätestens im Frühjahr 1791 als praktischer Arzt in Altensteig nieder ${ }^{13}$. Doch hier sollte er nicht lange wirken: schon am

Cannstatt 1989; Ders., Schwarzbrot und Freiheit. Die Tübinger Studentenbewegung zur Zeit Hölderlins und Hegels, in: Bausteine zur Tübinger Universitätsgeschichte, hg. von Volker Schäfer, Bd.6, Tübingen 1992, S. 9-62; Ders./Jörg Schweigard, Freiheit oder Tod! Die deutsche Studentenbewegung zur Zeit der Französischen Revolution, Köln 2005, S. 122 128, 137-139. Vom 4. bis 7. Oktober 1790 hielt sich Dobel bei der Pfarrfamilie seines Freundes Gottlieb Friedrich Rau (1766-1829) in Hemmingen auf (vgl. Stb. Dobel Nr. 39, 41, 43, 45, 59, 62), dessen Nachfolge als Pfarrer von Plattenhardt Eduard Mörike antrat und sich mit dessen Tochter Luise (1806-1891) verlobte.

9 Über Myositis und Neuritis, besonders rheumatische, an der Geschichte einer Kranken veranschaulicht, Tübingen 1790, 28 S. (online gestellt); Universitätsbibliothek Tübingen Ja 222.4-18, und öfter; Bibliothek des Evangelischen Stifts Tübingen oct. 9305-5.

10 Kresse.

11 Repertorium der medicinischen Litteratur des Jahres 1790, hg. von Paulus Usteri, Zürich 1791, S. 239, Nr. 96; vgl. auch Medicinisch-chirurgische Zeitung, hg. von J.J. HarTenKeil/F. X. Mezler, Salzburg 1791, Bd. 1, Nr. 17, S. 319 f.; Medicinisches Schriftsteller-Lexicon der jetzt lebenden Aerzte, Wundärzte, Geburtshelfer, Apotheker und Naturforscher aller gebildeten Völker, hg. von Adolph Carl Peter Callisen, Bd.5, Copenhagen 1831, S. 238, Nr. 616, 1584.

12 Dekanatsbuch der Medizinischen Fakultät, Universitätsarchiv Tübingen 14/14, S. 417 (freundliche Auskunft von Frau Irmela Bauer-Klöden).

13 Vgl. die Stammbuchwidmungen Nr. 9, datiert Tübingen, 22. Oktober 1790, und Nr. 29, datiert Altensteig, Mai 1791. Verständlicherweise fällt fast die Hälfte der Einträge in die Zeit von Dobels Abschied von der Universität in den September (62) und Oktober (22) 1790. Im April 1791 war Dobel noch einmal für einige Tage in Tübingen (vgl. Stb. Dobel Nr. 170 und 171 vom 7. April 1791 und Nr. 156 und 198 vom 10. April 1791). Bei dieser Gelegenheit revanchierte er sich für eine Freundschaftswidmung im Stammbuch von Johann Christian Albrecht Ernst Camerer (1768-1792). Vgl. Stb. A.E. Camerer (wie Anm. 69) Bl. 133; Anm. 67. Nach Altensteig könnte Dobel über Johann David Krafft (1754-1797) gekommen sein, der dort seit 1784 als Diakonus amtierte (vgl. Anm. 14). Bei dessen Vater, Johann Ehrenreich Krafft (1717-1792), Pfarrer in Pliezhausen, einer Nachbargemeinde von Rommelsbach, vikarierte Dobels älterer Bruder Johann Friedrich seit Oktober 1789 (FABer (wie Anm. 4) LXIV \471a; Vikarbuch Landeskirchliches Archiv Stuttgart A 12, Nr.23, Bd.3, S.101). Beide schrieben dort am 28. Dezember 1789 in sein Stammbuch (Nr. 133, E. Krafft Nr. 147: Nil temere, rückseitig Hölderlin, vgl. Anm. 37).

Zeitschrift für Württembergische Landesgeschichte 74 (2015), S. 99-119.

(C) Kommission für geschichtliche Landeskunde in Baden-Württemberg und Württembergischer Geschichts- und Altertumsverein e.V.

ISSN 0044-3786 
27. Juli 1792 starb Christian Amandus Heinrich Dobel nachmittags um halb drei Uhr am „Schleim- und Brandfieber“ (Typhus) und wurde drei Tage darauf abends vier Uhr mit Gebet in Altensteig beerdigt ${ }^{14}$. Mit seinen nur 22,5 Jahren war ihm die kürzeste Lebenszeit der Freunde beschieden. Sein Stammbuch kam zunächst an den Vater ${ }^{15}$, dann aber wohl an den nächstjüngeren Bruder Carl Emanuel (17711837), Geheimer Registrator beim Kriegsministerium in Karlsruhe ${ }^{16}$, womit der Weg ins Badische eine Erklärung fände.

\author{
Hegel - Schelling - Hölderlin \\ Glüklich wer auf seinem Pfad \\ einen Freund zur Seite hat! \\ Dreimal glüklich aber ist, \\ wen sein Mädchen feurig küst!!
}

Diesen ebenso wenig geistreichen wie originellen Spruch schrieb Georg Wilhelm Friedrich Hegel seinem Freund Dobel am 27. August 1790 ins Stammbuch ${ }^{17}$ (Abb. 3). Der nachmalige Philosoph von Weltrang gab sich mit solchen Widmungen

${ }^{14}$ Das heißt ohne Leichpredigt - übrigens durch Diakonus Krafft (wie Anm. 13); Totenregister Altensteig, Landeskirchliches Archiv Stuttgart KB 1606, Bd.12, S.226. Der letzte Eintrag in Dobels Stammbuch datiert Altensteig, März 1792 (Nr.21). Im April schrieb Christian Dobel in Altensteig seine letzte überlieferte Freundschaftswidmung in ein Album. Sie gilt August Eberhard Ludwig Stahl (1763-1828), Kompromotional von Carl Philipp Conz (wie Anm. 50), zuletzt Registrator beim Konsistorium in Stuttgart, dessen Verlobte in Calw lebte, und zitiert Jean de La Bruyère: Laune und Eigensinn finden sich immer nabe bei der Schönheit, wie das Gegen Gifft bei der schädlichen Pflanze. Denn diese würde one jene den Mauern weit gefährlicher sein, und ibre HerzensWunden würden nicht so leicht heilen. Privatbesitz, Kopie Universitätsarchiv Tübingen S 128/76, Bl.89; vgl. Gebhardt (wie Anm. 8) S. 503; SchäFer, Nachrichten (wie Anm. 33) S. 352, Anm. 99.

${ }^{15}$ Zum ersten Eintrag in Dobels Stammbuch (Nr.157), unterzeichnet mit „Bruder“ und datiert Tübingen 20. Januar 1789, von Johann Gottfried Faber (1769-1794), Pfarrerssohn von Gaisburg, zuletzt praktischer Arzt in Esslingen, Keine Wollust hat je den rüstigen Jüngling geschwächt, und mein nervichter Arm breche die Sense dem Tod, bemerkt Pfarrer Dobel ist ein Lügner - an sich selbst zeigte sich das Gegentheil ao. 1794 da er vom Sensenmann überweltiget worden. Gottfried Faber starb wie Christian Dobel an Typhus. Sein gleichnamiger Vater war der unmittelbare Vorgänger von Dobel senior im Feldpredigeramt. Vgl. MUT, Nr.38557; Faber (wie Anm.4) III $\$ 284 B$; BWKG 1906, S. I30; Stb. C.C. Camerer (wie Anm. 43) Bl.24v.

${ }_{16}$ Vgl. Großherzoglich-Badisches Regierungsblatt 1810, Nr. XXIII (9. Juni) S. 184; Hofund Staatshandbuch des Großherzogthums Baden 1834, Carlsruhe 1834, S. 135. Carl Emanuel Dobel lithographierte 1823 ein Gedenkblatt an die Pforzheimer Opfer der Schlacht bei Wimpfen von 1622. Vgl. GLAK 69 Baden, Sammlung 1995 G Nr. 45.

17 Denke bei diesem Blättchen an deinen Freund C[andidatus] Hegel aus Stuttg[ardt]. Tübingen d[en] 27 Aug[ust] 1790.; Stb. Dobel Nr. 115. Allein in Dobels Stammbuch kommt das Verschen in Varianten noch dreimal vor (Nr. 14, 94, 137). 


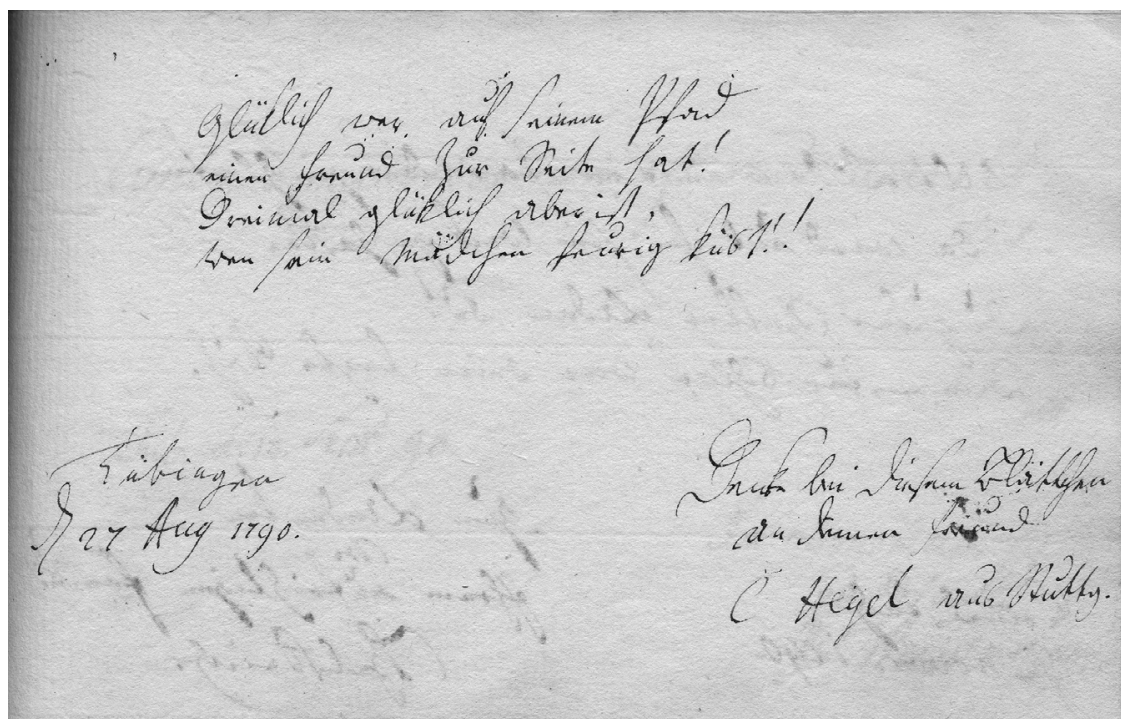

Abb. 3

offenbar nur wenig Mühe, setzte er doch denselben Reim eine Woche später dem Kommilitonen Fink ins Album ${ }^{18}$. Seinen Platz fand er neben Bernhard Friedrich Kind, über dessen Text er oben rechts kritzelte Grüß Gott Kind! ${ }^{19}$ Unterschrieben

18 Eintrag vom 4. September 1790, Original verschollen, vgl. Briefe von und an Hegel, hg. von Friedhelm Nicolin, Hamburg ${ }^{3}$ 1977, Bd. 4/1: Dokumente und Materialien zur Biographie, S. 165. Johann Christoph Friedrich Fink (1770-1844) von Königsbronn war zuletzt Pfarrer in Söhnstetten; Stb. Dobel Nr.15: Der Himmel seegne dich, mein guter Dobel!! (März 1790); Stb. Faber (wie Anm. 47) Bl.137v; Stb. Hegel (wie Anm. 38) Bl. 15, Nicolin (wie oben) S. 149; Stb. Hiller (wie Anm. 40) Bl. 62v mit Silhouette; Stb. Rueff (wie Anm. 41) Bl. 83 mit Silhouette; Stb. Süskind (wie Anm. 22) Bl.6; vgl. auch Kunn, Schwarzbrot (wie Anm. 8) S. 27, 48-50, 57f.; Kunn/Schweigard (wie Anm. 8) S. 137, 149, 272, 276. Auch Hegels Texte für Johann Christian Ehemann (1771-1849) und Christian Friedrich Hiller (17691817) von Nordheim (Stb. Dobel Nr.111) sind identisch (vgl. Nicolin (wie oben) S.166f.; Anm. 40).

${ }_{19}$ Bernhard Friedrich Kind (1768-1845) von Mönchweiler, zuletzt Pfarrer in Kuppingen, hatte sich wohl kurz zuvor - er datiert nur August 90. - mit Hiob 1,21 verewigt: Nakt bin ich von meiner Mutter Leibe kommen; nakt werde ich wieder dabin fabren; Stb. Dobel Nr. 114; Stb. Hegel (wie Anm. 38) Bl. 34, Nicolin (wie Anm. 18) S. 141; Stb. Schmoller (wie Anm. 69); Stb. Weigelin (wie Anm. 42) Bl.37. Auf der Rückseite von Hegels Eintrag findet sich die Freundschaftswidmung von Johann Carl Christoph Helfferich (1770-1835) von Lotenberg, gestorben als Pfarrer in Pleidelsheim, datiert Rommelsbach, November 1790. Stb. Faber (wie Anm. 47) Bl.58v; Stb. Weigelin (wie Anm. 42) B1.35. Helfferichs Stammbuch ist nur fragmentarisch überliefert (14 Bl., 1791-1794, WLB Cod.hist.oct.122) mit vier identischen Einträgern, darunter Hiemer (wie Anm. 57) Bl. 6 und Weigelin (wie Anm. 42) Bl.14; vgl. auch Anm. 39. 
hat Hegel, von dem bislang 13 Stammbuchblätter aus der Gymnasial- und Studienzeit bekannt waren ${ }^{20}$, mit dem Kürzel „C“ für „Candidatus“ vor seinem Namen, da er kurz vor dem Magisterexamen stand ${ }^{21}$.

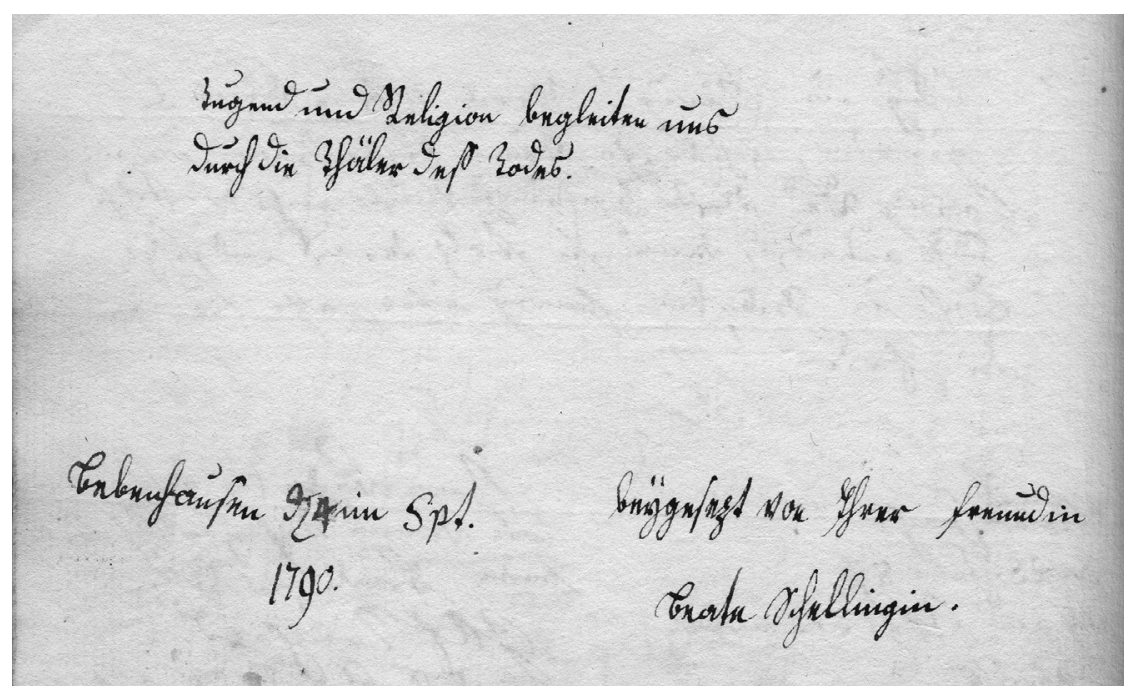

Abb. 4

Auch der Name Schelling begegnet in Dobels Stammbuch, doch handelt es sich nicht um den berühmten Friedrich Wilhelm Joseph, der erst im Oktober 1790 die Universität Tübingen bezog und von dem überhaupt nur drei studentische Freundschaftswidmungen überliefert sind ${ }^{22}$, sondern um dessen Schwester Beate Schelling

${ }^{20} \mathrm{Zu}$ den bei Nicolin (wie Anm. 18) S. 165-168 veröffentlichten Albumblättern kommen noch die für einen Unbekannten vom Juni 1785, Städtische Sammlungen Tübingen, Inv.Nr.1100, für David Friedrich Leypold, Stuttgart 23. Juni 1786, WLB Cod.hist.oct.176, Bl. 150v, für Felix Buttersack (wie Anm. 48) und Johann Philipp Weigelin, datiert Tübingen 5. Juni 1791 (wie Anm. 42); vgl. SснӓғER, Neue Stammbuchblätter 2005 (wie Anm. 1) S. 310315.

${ }^{21}$ So auch auf dem Stammbuchblatt vom 5. September 1790 für Georg Christoph Friedrich Rueff (1768-1818) von Neuhausen/Erms, zuletzt Pfarrer in Geifertshofen, Einzelblatt, WLB Cod.poet.et.phil.fol.63,V,k (vgl. Anm. 41); Nicolin (wie Anm. 18) S.166, zu Hegels Magisterexamen ebd., S. 280-287. Vermutlich war der Eintrag für Fink ebenso mit „C“ unterzeichnet (wie Anm. 18). Die Einträge im Stammbuch Hegels setzen erst im Februar 1791 ein, und als sich Dobel im April dieses Jahres noch einmal in Tübingen aufhielt, war Hegel krankheitshalber bei seiner Familie in Stuttgart, so dass es zu keinem Gegeneintrag kam; vgl. Stammbuch Hegel (wie Anm.38); Nicolin (wie Anm. 18) S.47; vgl. auch Anm.13; Wolfgang SснӧLlкорғ, „Stimmung äußerst demokratisch“. Die Studienzeit des Georg Friedrich Hegel im Tübinger Stift, in: Bausteine (wie Anm. 8) Bd. 2, 1984, S. 81-105.

${ }_{22}$ Für Christian Friedrich Hiller (wie Anm. 40) Bl. 160 mit Silhouette, Johann Christian Ehemann und Johann Gottlob Süskind (1773-1838). Vgl. F. W.J. Schelling, Historisch-kriti- 
(1779-1861), nachmals verehelichte Groß in Stuttgart ${ }^{23}$. Mit Datum Bebenhausen $d[e n] 4 \mathrm{im}$ S[e]pt[ember]. 1790 gab sie dem Medizinstudenden den für ein elfjähriges Mädchen bemerkenswerten Satz mit auf den Weg: Tugend und Religion begleiten uns durch die Thäler deß Todes ${ }^{24}$ (Abb. 4). Vielleicht kam der Kontakt durch den älteren Bruder Johann Friedrich Dobel zustande, der einige Jahre zuvor Schüler von Joseph Friedrich Schelling (1737-1812) in Bebenhausen gewesen war ${ }^{25}$, vielleicht sogar durch Hölderlin, der den „Fritz“ ja schon von Nürtingen her kannte.

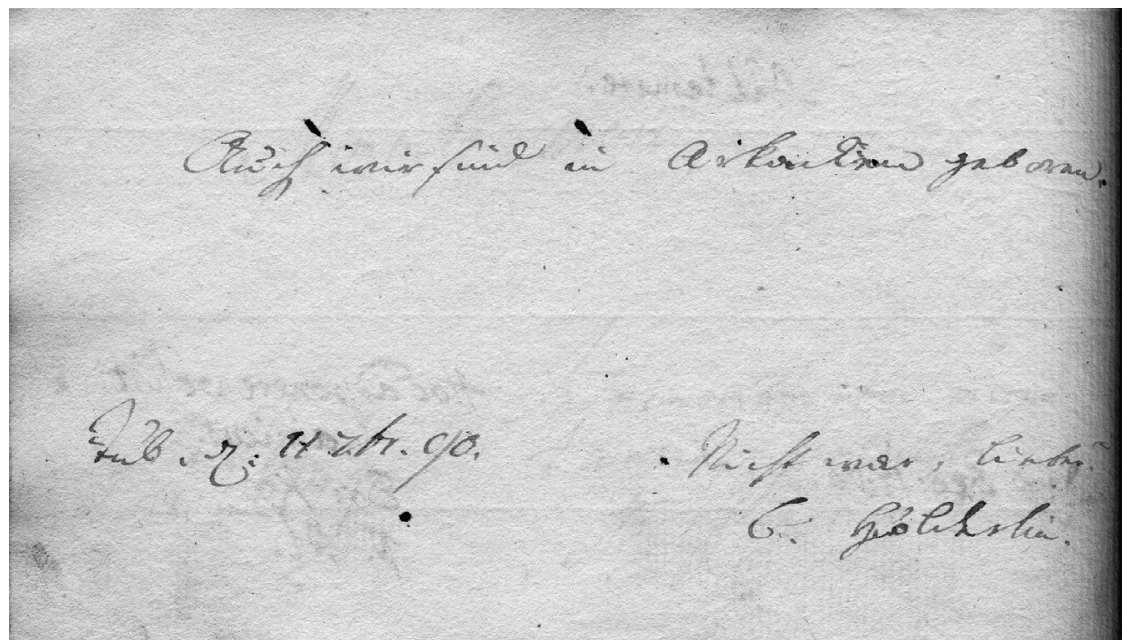

Abb. 5

Auch wir sind in Arkadien geboren.

Tüb[ingen]. d[en]. 117 [septem]br[is] $90 . \quad \quad$ Nicht war, Lieber?

C. Hölderlin.

sche Ausgabe, Reihe III, Briefe, Bd.1, Briefwechsel 1786-1799, hg. von Irmgard MölleR/ Walter Schieche, Stuttgart 2001, S. 261; Volker Schäfer, „Das Gefährlichste für den Menschen ist - Ruhe! “. Schelling im Stammbuch seines Tübinger Studienfreundes Süskind, in: Wege und Spuren. Festschrift Joachim-Felix Leonhard, Berlin 2007, S. 635-660. Im Stammbuch Süskind (164 Bl., 1793-1803, Privatbesitz) hat sich auch Hölderlin eingetragen. Vgl. Schäfer, Neue Stammbuchblätter (wie Anm. 1) 2005, S. 315-323 und Anm. 29.

23 Sie nahm 1812 die verwitwete Mutter Maria Gottliebin Schelling geb. Cless (1746-1818) in ihren Haushalt auf. Mit Beate Schelling - eine Nichte von Hölderlins Nürtinger Lehrer Nathanael Köstlin - verstarb 1861 die letzte Einträgerin. Vgl. auch Anm. 5, 71.

${ }^{24}$ Be ygesezt von Ihrer Freundin Beate Schellingin; Stb. Dobel Nr. 66. Die Sentenz scheint damals verbreitet gewesen zu sein. Vgl. Mein Stammbuch. Für tugendliebende Freunde und Freundinnen. Aus den Quellen edler Seelen geschöpft, verlegt bei Carl Gotthold Benjamin Fritzsch, Buchhändler in Lindau, Frankfurt/Leipzig 1783, S. 41, Nr. 103.

${ }^{25}$ Vgl. Anm. 7. 
Es ist eine Reminiszenz an den von ihm so verehrten Schiller, die Hölderlin für seinen Freund Dobel wählt (Abb. 5) - das Wort „Arkadien“ ist hier erstmals in Hölderlins Handschrift überliefert! ${ }^{26}$ Das Gedicht, auf dessen erste Strophe er sich bezieht, trägt den bezeichnenden Titel „Resignation“ und erschien 1786 in Schillers Zeitschrift „Thalia“27:

„Auch ich war in Arkadien geboren, auch mir hat die Natur an meiner Wiege Freude zugeschworen, auch ich war in Arkadien geboren, doch Tränen bracht' der kurze Lenz mir nur.“

Volker Schäfer hat darauf aufmerksam gemacht, dass bei Hölderlin „eine sorgfältig überlegte, auf die jeweiligen Empfänger abgestimmte Wahl seiner Stammbuchtexte zu beobachten“ ist, er aber ,in der Regel nur konventionelle, fast unpersönliche Widmungen setzte“ wie „von Deinem Hölderlin“, „von Deinem Freund Hölderlin“, „Schriebs zum Andenken Dein Freund Hölderlin“28. Nur einmal, für

${ }^{26}$ Frühe Nachweise in Hölderlins Lyrik: (An die Schönheit: „arkadische Gestalt“ 1791); Kanton Schweiz. An meinen lieben Hiller: „Arkadiens Friede“ 1792; Hymne an die Freundschaft. An Neuffer und Magenau: „in Arkadia“ 1792; An Hiller: „Zauberisches Arkadien“ 1793; Das Schicksal: „wohl ist Arkadien entflohen“ 1793; in Briefen nur an Neuffer, Waltershausen 10. Oktober 1794: „daß die Welt kein Arkadien ist“; in Übersetzungen nur Pindar, Pythische Ode III: „Betten von Arkadia“ 1800. Vgl. Friedrich Hölderlin, Sämtliche Werke, „Frankfurter Ausgabe“ (künftig: FHA), Bd. 2: Lieder und Hymnen, hg. von Dietrich Eberhard SATtlen, Frankfurt am Main 1978, S. 118/48, 175/58, 197/61; ebd., Bd. 3: Jambische und hexametrische Formen, Frankfurt am Main 1977, S. 24/45, S.37/29; ebd., Bd.18: Briefe 1, Frankfurt am Main/Basel 1993, S.184f.; ebd., Bd. 19: Stammbuchblätter, Widmungen und Briefe II, Frankfurt am Main/Basel 2007, S. 198/55f.; ebd., Bd. 15: Pindar, Frankfurt am Main/Basel 1987, S. 229/45.

27 Resignation. Eine Phantasie, in: Thalia 1786, Bd.1, Heft 2, Nr. V, S.64-69; vgl. auch Günter Mieth, Friedrich Hölderlin - Zeit und Schicksal. Vorträge 1962-2006, Würzburg 2007, S. 66f. Auch Hölderlins Freund Jakob Friedrich Märklin zitiert aus diesem Gedicht (vgl. Anm. 53) und mit der letzten Zeile trägt sich seine Mutter Friederike Märklin geb. Rapp (1743-1804) am 24. September 1790 in Dobels Stammbuch ein (Nr. 144): Was man von der Minute ausgeschlagen, gibt keine Ewigkeit zurück. Nur einmal hat Hölderlin ein gekennzeichnetes Schillerzitat für eine Freundschaftswidmung verwendet, nämlich für Johann Christian Benjamin Rümelin (1769-1821), datiert Maulbronn, 18. Dezember 1786. Vgl. FHA, Bd.1: Gedichte 1784-1789. Stammbuchblätter und Widmungen I, Frankfurt am Main/Basel 1995, S. 548; FHA, Bd. 19 (wie Anm. 26) S. 46. Ende August 1792 schreibt Hölderlin an Neuffer: „so siz ich zwischen meinen dunklen Wänden, und berechne, wie bettelarm ich bin an Herzensfreude, und bewundre meine Resignation“; FHA, Bd.18 (wie Anm. 26) S. 129;FHA, Bd. 19 (wie Anm. 26), S. 142/2-4.

28 Volker SCHÄFER, Ein unbekanntes Stammbuchblatt des jungen Hegel, in: „... aus der anmuthigen Gelehrsamkeit“. Tübinger Studien zum 18. Jahrhundert, Festschrift Dietrich Geyer, hg. von Eberhard Müller, Tübingen 1988, S. 99-105, hier S. 105; auch in: Ders., Aus dem Brunnen (wie Anm. 1) S. 260-265, hier S. 265; Ders., Neue Stammbuchblätter 2005 (wie Anm. 1) S. 321; FHA, Bd. 1 (wie Anm. 27) S. 551-562. 
Johann Gottlob Süskind (1773-1838), geht er darüber hinaus: „Nimm diesen Spruch aus deinem u. meinem Herzen zum Andenken. Dein Freund Hölderlin“29. Auch für Christian Dobel macht Hölderlin diese Ausnahme: Er drückt durch das „wir“ eine verbindende Gemeinsamkeit aus - noch unterstrichen durch das „nicht wahr“ - und nennt ihn vertraut „Lieber“ ohne weiteren Zusatz, was er sonst bei keiner seiner Widmungen macht. Dies weist wohl auf eine intimere Freundschaft zwischen den beiden hin. Verband sie die stark gefühlte Bestimmung („Natur“) zu Kunst und Poesie („Freude“) in Sehnsucht nach einer idealisierten Antike („Arkadien“) auf der einen und das Leiden an einem aufgezwungenen Studium („Tränen im Lenz") auf der anderen Seite? Wem gegenüber ist das „auch wir“ gesprochen? Vielleicht gegenüber dem Landschaftsmaler und Radierer Johann Christian Reinhart (1761-1847), der ein Cousin Dobels war ${ }^{30}$ Reinhart, Sohn eines Pfarrers und früh Halbwaise, hatte wie Hölderlin dem Wunsche seiner Mutter folgend in Leipzig mit dem Theologiestudium begonnen, konnte sich aber schon bald ganz der Kunst widmen. Mit Schiller war er seit 1785 befreundet und porträtierte ihn in der bekannten Zeichnung mit Hut und Pfeife auf einem Esel reitend ${ }^{31}$. Es zog Reinhart nach Italien: $\mathrm{Zu}$ Weihnachten 1789 traf er in Rom ein und blieb. Bereits aus dem Jahr 1785 gibt es eine Federzeichnung des Künstlers, bezeichnet „Et in Arcadia ego“, „Auch ich in Arkadien“32. Spielt Hölderlin auf diesen Vetter seines Freundes

29 Schäfer, Neue Stammbuchblätter 2005 (wie Anm. 1) S.321. Von der Widmung „aus brüderlichem Herzen“ für seinen Halbbruder Carl Gok (1776-1849) ist in diesem Zusammenhang abzusehen (FHA, Bd.1 (wie Anm.27) S. 556, 562; FHA, Bd. 19 (wie Anm. 26) S. 107).

30 Reinharts Mutter Magdalena Wilhelmina Friederica geb. Müllner (1730-1784) war Dobels Tante (vgl. Anm. 4). Der Bruder des Künstlers, Johann Amandus Friedrich Reinhart (1762-1834), zuletzt Pfarrer in Lenkersheim, trug sich am 28. Juli 1789 in Rommelsbach als „Bruder und Vetter" in Dobels Stammbuch ein (Nr.65). Er hielt seinem Schulkameraden Johann Paul Friedrich Richter, dem Dichter Jean Paul, dem er als Gymnasiast einen üblen Streich gespielt hatte, 1825 die Leichpredigt. Vgl. Karl Greim, Die Vorfahren des deutsch-römischen Landschaftsmalers Johann Christian Reinhard aus Hof, in: Miscellanea curiensia. Beiträge zur Geschichte und Kultur Nordoberfrankens und angrenzender Regionen 6 (2006) S. 165-179, hier S. 167 f.; Dieter Richter, Von Hof nach Rom. Johann Christian Reinhart. Ein deutscher Maler in Italien. Eine Biographie, Berlin 2010, S. 23 f.; vgl. auch Jean Paul, Wahrheit aus Jean Pauls Leben. Drittes Heftlein, Breslau 1828, S. 29-31; Fikenscher (wie Anm. 5) Bd. 7, 1804, S. 170.

${ }^{31}$ Sie entstand 1787 in Meiningen. Eine weitere Porträtzeichnung Reinharts diente seinem Freund Thorwaldsen als Vorlage für das Schillerdenkmal in Stuttgart. Vgl. Richter (wie Anm. 30) S. 46f.; Johann Christian Reinhart. Ein deutscher Landschaftsmaler in Rom, Ausstellungskatalog, hg. von Herbert W. Rotт/Andreas Stolzenburg, München 2012, S. $38 \mathrm{f} ., 182 \mathrm{f}$.

32 Reinhart, der auch lyrisches Talent besaß und seine Produkte Schiller vorlegte, könnte die Entstehung des Gedichtes „Resignation“ mitbekommen haben und so zu seiner Zeichnung inspiriert worden sein. Vgl. RotT/Stolzenburg (wie Anm. 31) S. 36, 39-41, 141. „Et in Arcadia ego" ist urspünglich eine Grabinschrift, die auf den Tod zielt, ein Memento mori: „Auch in Arkadien bin ich zur Stelle“. Erst seit dem 17. Jahrhundert wird sie als Aussage des 
an, dem unter vergleichbaren Voraussetzungen ein besseres Los beschieden war als Dobel und ihm, der seiner Bestimmung folgen, seine Erfüllung finden durfte ${ }^{33}$

Hölderlins Stammbucheintrag für Christian Dobel steht chronologisch zwischen den Widmungen für seinen Halbbruder Carl Gok, datiert Tübingen, 1. August 1790 - bzw. Georg Christian Friedrich Rueff, zwar ohne Datum, von der Forschung aber auf den 5. September 1790 festgelegt - und Georg Wilhelm Friedrich Hegel, datiert Tübingen, 12. Februar $1791^{34}$. Wie Hegel stellt Hölderlin als „Candidatus Magisterii“ seit März 1790 bei seinen Widmungen das „C“ vor den Namen ${ }^{35}$. Es könnte hier letztmalig geschehen sein, da die Promotion zum Magister bereits am 22. September 1790 erfolgte $^{36}$. Den Platz für seine Freundschaftswidmung wählte Hölderlin links gegenüber dem Eintrag von Carl Ludwig Reyscher (1770$1837)^{37}$, wofür er eine Rückseite in Kauf nahm.

Sprechers gedeutet. Vgl. Erwin Panofsky, Et in Arcadia ego. Poussin und die Tradition des Elegischen, hg. von Volker BREIDECKER, Berlin 2002.

${ }^{33}$ Magenau zufolge sprach Hölderlin 1795 von einer Reise nach Rom. Vgl. Volker ScH ̈̈fer, Nachrichten zu Hölderlins Freunden Magenau, Neuffer und Rosine Stäudlin, in: Ders., Aus dem Brunnen (wie Anm. 1) S. 330-360, hier S. 337. Vgl. auch Anm. 45, 55.

${ }^{34}$ FHA, Bd. 1 (wie Anm. 27) S. 556-557; FHA, Bd. 19 (wie Anm. 26) S. 107, 109 f., 118; vgl. auch Anm. 21, 29, 41. Hölderlin hat nur die Hälfte der (mit Dobel) 22 bisher bekannt gewordenen Stammbuchblätter seiner Seminar- und Studienzeit voll datiert (wie Anm. 28). Er ist der einzige Freund, der sich an diesem Samstag in Dobels Stammbuch eintrug - am 10. und 12. September 1790 waren es jeweils drei, unter letzteren „Mithospes“ Friedrich August Köhler (1768-1845), nachmals Pfarrer in Marschalkenzimmern und landeskundlicher Schriftsteller, der kurz darauf, am 23. September, seine Albreise antrat (Stb. Dobel Nr. 47; Stb. J.C. Camerer (wie Anm. 44) Bl. 51v; Stb. Schmoller (wie Anm. 69) Bl.165). Vgl. Friedrich August KöHLER, Eine Albreise im Jahre 1790 zu Fuß von Tübingen nach Ulm. Ein Lesebuch zur historischen Landschaft der Schwäbischen Alb, hg. von Eckart Frahm/Wolfgang KAsснuвa/Carola Lipp, Bühl-Moos 1984. Von den 25 von Georg Schmidgall notierten Namen aus dem verschollenen Stammbuch Köhlers begegnen acht im Album Dobels, darunter Hiller (wie Anm. 40), Memminger (wie Anm. 54) und Schmoller (wie Anm. 69). Vgl. Universitätsarchiv Tübingen, Sammlung Schmidgall 214-529.

35 Vgl. die Widmungen für Clemens Christoph Camerer (1766-1826, Stb. Dobel Nr. 57) und Friedrich Philipp Immanuel Niethammer (1766-1848) vom März 1790 und für Georg Christoph Friedrich Rueff (wie Anm. 41). Bei seinem Halbbruder Carl Gok sieht Hölderlin freilich von diesem akademischen Titulus ab. Vgl. FHA, Bd. 1 (wie Anm. 27) S. 555f.; FHA, Bd. 19 (wie Anm. 26) S. 106 f., 110.

${ }_{36}$ MUT, Nr. 38622; Hölderlin in Tübingen, bearb. von Werner Volke (Marbacher Magazin 11, Sonderheft), Marbach/Neckar ${ }^{4} 2001$, S. 24, 29.

37 Stb. Dobel Nr. 149: Unsere Freundschafft soll bestehen, bis der Tod eine Ende macht. (7. September 1790). Reyscher, der 1796 Charlotte Le Bret (1776-1839) heiratete - eine Schwester von Hölderlins „Lyda“ - ist der Vater des Tübinger Juraprofessors und Rechtsanwalts August Ludwig Reyscher (1802-1880), Herausgeber der württembergischen Gesetze. Vgl. Hayden-Roy (wie Anm.7) S.242f.; Anm. 59, 60; Kunn, Schwarzbrot (wie Anm. 8) S. 57; Kuhn/Schweigard (wie Anm. 8) S. 272; zum vorderseitigen Eintrag Anm. 13. 


\section{Der Freundeskreis}

Wie sein Album amicorum ausweist gehörte Christian Dobel zum Freundeskreis um Hölderlin und Hegel: 31 Einträger begegnen auch im Stammbuch Hegels $^{38}$, bereits zehn im Denkendorfer Stammbuch Hölderlins - ein von der Forschung vermutetes zweites Tübinger Album gilt als verloren ${ }^{39}$. In den überlieferten Freundschaftsalben von drei Einträgern haben sich Hegel und Hölderlin verewigt. Dabei handelt es sich um die Stammbücher von Christian Friedrich Hiller (17691817), das mit dem Album Dobels 37 weitere identische Personen aufweist ${ }^{40}$, Georg

38 Stb. Hegel (86 Bl., 94 Einträge, 1791-1794) Universitätsbibliothek Tübingen Mh 858 (online gestellt), publiziert bei Nicolin (wie Anm.18) S.135-164, Erläuterungen S.340342. Unter ihnen sind die Mömpelgarder Stipendiaten Georges Frédéric Fallot (1770-1839), seit 1811 Pasteur in Audincourt (Stb. Dobel Nr. 50: Es lebe der Wein), der die bekannte spöttische Zeichnung von Hegel als alter Mann beigefügt hat (Bl.33; Nicolin (wie Anm.18) S.135), und Georges Louis Bernard (geb. 1771), der Revolutionär (Bl.4; Nicolin (wie Anm. 18) S. 154; Stb. Dobel Nr. 121; vgl. auch Kunn, Schwarzbrot (wie Anm. 8) S. 20-22, 27, 32f., 35-39; Kunn/Schweigard (wie Anm. 8) S. 130-132, 136f., 141-143, 145 f., Silhouette Abb. 4: Bildunterschrift fälschlich Fallot) sowie August Ernst Philipp Lang (1769-1844) von Böblingen, seit 1794 Pfarrer in Schornbach, der sich scherzhaft als „Laura“ verewigte (Bl. 83; Nicolin (wie Anm. 18) S. 141; Stb. Dobel Nr. 112; Sснӓ fer, Neue Stammbuchblätter 2005 (wie Anm.1) S.310, Anm. 53).

39 Georg Ludwig Ade (1769-1838), Eintrag verloren, Namenregister, Bl. 119 (Stb. Dobel Nr. 78); Christian Ludwig Bilfinger (1770-1850), Bl. 28 (Stb. Dobel Nr.4); Carl Christoph Friedrich Bilfinger (1773-1838), Bl.78v (Stb. Dobel Nr. 5); Johann Jakob Efferenn (17701824), Bl.48, Stb. Hegel (wie Anm. 38) Bl. 10 (Stb. Dobel Nr. 162); Johann Christian Friedrich Elsner (1770-1806), Bl. 29v, Stb. Hegel (wie Anm. 38) Bl. 12 (Stb. Dobel Nr. 7); Fink (wie Anm. 18) Bl. 5; Helfferich (wie Anm. 19), Eintrag verloren, Namenregister, Bl. 120 (Stb. Dobel Nr. 116); Gottlieb Friedrich Lang (1769-1832), Bl. 30 (Stb. Dobel Nr. 61); Carl Christoph Renz (1770-1829), Bl.36 (Stb. Dobel Nr.183); Eberhard Friedrich Schweickhart (17701825), Bl. 31 (Stb. Dobel Nr. 58). In Hölderlins Stammbuch, vom Vater ererbt und fortgeführt, sind noch Widmungen von 19 Kompromotionalen vorhanden. Stb. Hölderlin (122 Bl., 1756-1786), WLB Cod.poet.et.phil.fol.63,V,h. (online gestellt); FHA, Bd.1 (wie Anm. 27) S. 525-548; FHA, Bd. 19 (wie Anm. 26) S. 30-40, 44-45, 79.

${ }^{40}$ Stb. Hiller (267 Bl., 1788-1800, mit Silhouette), WLB Cod.hist.oct.280 (online gestellt), Bl. 29 (Hölderlin mit Silhouette), Bl. 126 (Hegel); FHA, Bd.1 (wie Anm. 27) S. 551; FHA, Bd. 19 (wie Anm. 26) S. 82; Nicolin (wie Anm. 18) S. 167; Stb. Dobel Nr. 111, ein Zitat von Johann Wilhelm Ludwig Gleim: Rosen pflüke, Rosen blühn: Morgen ist nicht heut; Keine Stunde laß entfliehn, flüchtig ist die Zeit. (3. Dezember 1789); Stb. A.E. Camerer (wie Anm. 69) Bl. 96; Stb. Faber (wie Anm. 47) Bl. 59; Stb. Süskind (wie Anm. 22) Bl.31. Hiller, gestorben als Lehrer in Nürtingen, trug sich 1793 mit dem Gedanken, in die USA auszuwandern (vgl. „An Hiller“ wie Anm. 26). Sein Bruder Johann Gottfried Hiller (1768-1843), zuletzt Pfarrer in Wiernsheim, zählt ebenfalls zu Dobels Freunden (Stb. Dobel Nr. 84). Vgl. Georg Schmidgall, Die Französische Revolution und die Tübinger Studentenschaft. Das Stammbuch C.F. Hiller, in: Tübinger Blätter 35 (1946/47) S. 37-48; KunN, Schwarzbrot (wie Anm. 8) S. 16, 18 f., 21 f., 24 f., 29, 36 f., 41, 48f., 57f., 62; Kunn/Schweigard (wie Anm. 8) S. 63, 125, 131, 134 f., 138, 143, 145, 148 f., 272, 276, 280f., 283; Uwe Jens Wandel, Verdacht von Democratismus? Studien zur Geschichte von Stadt und Universität Tübingen im Zeitalter der Französischen Revolution (Contubernium, Bd. 31), Tübingen 1981, S. 53, 60 f.

Zeitschrift für Württembergische Landesgeschichte 74 (2015), S. 99-119.

(C) Kommission für geschichtliche Landeskunde in Baden-Württemberg und Württembergischer

Geschichts- und Altertumsverein e.V.

ISSN 0044-3786 
Christoph Friedrich Rueff (1768-1818) mit $35^{41}$ und Johann Philipp Weigelin (1769-1830) mit 31 gemeinsamen Freunden ${ }^{42}$. Hölderlin ist darüber hinaus noch vertreten in den Stammbüchern von Clemens Christoph Camerer (1776-1826), Liebschaft seiner Schwester Heinrike, mit 38 weiteren identischen Einträgern ${ }^{43}$, Johann Caspar Camerer (1772-1847) mit 27 - dazu noch Christian Dobel und seine Schwester Charlotte ${ }^{44}$-, Hegel mit einem Aphorismus von Goethe sowie Rudolf Magenau (1767-1846), dessen Album verschollen ist ${ }^{45}$. Die bis dato früheste

${ }^{41}$ Stb. Rueff, Blätter von Hölderlin, Hegel und Neuffer separat, WLB Cod.poet.et.phil. fol. 63, V,k, Bl. 1-2 (online gestellt); Stammbuch (133 Bl., 1783-1791), Universitätsarchiv Tübingen S 127/13; FHA, Bd. 1 (wie Anm. 27) S. 556; FHA, Bd. 19 (wie Anm. 26) S. 110; NicoLIN (wie Anm. 18) S.166; Stb. Dobel Nr. 54: Keine Freude sey vermißt, Jedes schöne Kind geküßt - Und es klage nur der Thor, daß er seinen Tag verlobr!! (18. Juli 1790) „Bruder“ (vgl. Anm. 8); Stb. Buttersack (wie Anm. 48) Bl.21v; Stb. A.E. Camerer (wie Anm. 69) Bl. 27; Stb. C. C. Camerer (wie Anm. 43) Bl. 33; Stb. Hegel (wie Anm. 38) Bl. 54, Nicolin (wie Anm. 18) S. 148f.; Stb. Hiller (wie Anm. 40) Bl. 56 mit Silhouette; vgl. auch Kunn, Schwarzbrot (wie Anm. 8) S. 21, 62.

42 Stb. Weigelin (86 Bl., 1791), Universitätsarchiv Tübingen S 127/39, Bl. 36 (von Hölderlin nur die erste Zeile, das Weitere von Neuffer), Bl. 53 (Hegel); FHA, Bd.1 (wie Anm. 27) S. 557; FHA, Bd. 19 (wie Anm. 26) S. 122f.; Schäfer, Neue Stammbuchblätter 2005 (wie Anm. 1) S. 301-311; Stb. Dobel Nr.120; Stb. Buttersack (wie Anm. 48) Bl.110v; Stb. Hegel (wie Anm. 38) Bl.62; Nicolin (wie Anm. 18) S. 140; Stb. Helfferich (wie Anm. 19) Bl.14; vgl. auch Kunn, Schwarzbrot (wie Anm. 8) S.20-22, 62; Kuhn/Schweigard (wie Anm.8) S. 130,132 .

43 Stb. C. C. Camerer (107 Bl., 1784-1796, mit Silhouette), WLB Cod.hist.oct.329 (online gestellt), Bl. 95, Heinrike Hölderlin, Bl.31v (vgl. Anm. 67); FHA, Bd. 1 (wie Anm. 27) S. 555; FHA, Bd. 19 (wie Anm. 26) S. 106; Stb. Dobel Nr. 57 „im Lamm“ (vgl. Anm. 79): Der Glüklichste stirbt unter Wünschen (o.D). Vgl. auch Hayden-Roy (wie Anm.7) S.234; Kunn, Schwarzbrot (wie Anm. 8) S. 29, 62; Kunn/Schweigard (wie Anm. 8) S. 138. - Dr. iur. Camerer war von 1805 bis 1819 Bürgermeister von Reutlingen und Mitglied der württembergischen Ständeversammlung. Er besaß einen Gutshof auf der Achalm, in dessen Gastwirtschaft Justinus Kerner und Ludwig Uhland verkehrten. Vgl. Biographisches Handbuch der w ürttembergischen Landtagsabgeordneten 1815-1933, bearb. von Frank RABERG, Stuttgart 2001, S. 112 f.; Grab Hoppenlaufriedhof Stuttgart, Abt. 4b, Nr. 770.

${ }^{44}$ Stb. J.C. Camerer (123 Bl., 1790-1796, mit Silhouette), WLB Cod.hist.oct.319 (online gestellt) Bl. 46; FHA, Bd. 1 (wie Anm. 27) S. 562; FHA, Bd. 19 (wie Anm. 26) S. 217; Eintrag Dobel ebd., Bl.73, der Schwester Bl. 72; vgl. Anm. 64, 68; vgl. auch Kunn, Schwarzbrot (wie Anm. 8) S. 21, 29, 62; Kunn/Schweigard (wie Anm. 8) S. 130, 138, 415.

45 Stb. Hegel (wie Anm. 38) Bl. 32; Nicolin (wie Anm. 18) S. 136; bei Magenau Text bekannt, FHA, Bd. 19 (wie Anm.26) S.167; Stb. Dobel Nr.109, ein Vierzeiler von Gottlieb Konrad Pfeffel: Ein Schloß, das Buben in sich faßet, hat für den Weisen keinen Glanz, und wer nicht ganz das Laster haßet, der liebt die Tugend auch nicht ganz. (8. Juli 1789); Stb. Hiller (wie Anm. 40) Bl.61; Stb. Rueff (wie Anm. 41) Bl.6; Stb. Schmoller (wie Anm. 69) Bl. 48; vgl. auch NDB, Bd.15, Berlin 1987, S. 650 f.; Hayden-Roy (wie Anm. 7) S. 164-198 und öfter; Anm. 26. Unter den elf engeren Studienfreunden, die Magenau in der „Skizze meines Lebens" namentlich nennt, sind neben Hölderlin und Neuffer (wie Anm. 55) in Dobels Stammbuch vertreten: Johann Friedrich Breitschwerdt (1768-1824), Rektor in Ludwigsburg (Stb. Dobel Nr. 113); Friedrich Wilhelm Duttenhofer (1768-1805), psychisch erkrankt seit 1803 in Botnang bei Pfarrer Friedrich Lächelin (1759-1820), der auch als Pfleger für 
Freundschaftswidmung Hölderlins, ein Zitat von Klopstock, datiert Nürtingen 1. Oktober 1786, findet sich im Album des Theologiestudenten Johann Gottfried Carl Merian aus Mecklenburg. Es enthält neben Einträgen von 19 Freunden Dobels auch eine Widmung von ihm selbst sowie von seinem Bruder Johann Friedrich, beide vom November $1787^{46}$. Das Stammbuch Johann Carl August Fabers (17721836), in das sich Hölderlin im September 1789 einschrieb, teilt mit dem Dobels 34 Freunde $^{47}$, das von Felix Buttersack (1768-1853), in dem Hegel schon 1787 seine Freundschaft bekundete $21^{48}$.Wie Hölderlin und Hegel subskribierte auch Dobel den Gedichtband des Stiftsrepetenten Carl Philipp Conz (1762-1827), der 1792 erschien $^{49}$. Es könnte dies im April 1791 geschehen sein, als er sich noch einmal für einige Tage in Tübingen aufhielt und Conz ihm die vielzitierte Weisheit nach Hippokrates Ars longa vita brevis in Stammbuch schrieb ${ }^{50}$. Weitere 18 von Dobels Stammbuchfreunden finanzierten das Bändchen auf diese Weise vor, mit ihm also 21 von den rund 25 Tübinger Studenten insgesamt! ${ }^{51}$ So wird man mit einem

Hölderlin in Betracht gezogen wurde (Stb. Dobel Nr. 139; HAY DEN-Roy (wie Anm. 7) S. 284; Anm. 51); Gottlieb Jakob Guoth (1767-1850), zuletzt Pfarrer in Salach (Stb. Dobel Nr. 154); Kind (wie Anm. 19) und Theodor Gottfried Thomas (1768- nach1824), Legationsrat und Geheimsekretär der Königin Mathilde von Württemberg (Stb. Dobel Nr. 106). Vgl. WLB Cod. hist.qt.561, S. 31.

46 Stb. Merian (115 Bl., 1785-1802, mit Silhouette), WLB Cod.hist.oct.339 (online gestellt), Bl.36v (Hölderlin), Bl. 98 (J.F. Dobel), vgl. Anm. 1. Christian Dobel schreibt (Bl.28v): In bittrer Trennung labe der Gedanke mich, daß Du mich liebest! Interessant ist das hinzugesetzte „Damenkürzel“, die Initialen eines umschwärmten Mädchens vor einem „V“ für „Vivat“, hier V.J.M., was für „Vivat Johanne Märklin“ stehen könnte. Vielleicht war Dobel später sogar mit ihr verlobt - dann wäre die starke Präsenz der Familie Märklin in seinem Stammbuch erklärlich. Vgl. Anm. 71.

47 Stb. Faber (139 Bl., 1786-1800, mit Silhouette), WLB Cod.hist.oct.336 (online gestellt), Bl. 117; FHA, Bd. 1 (wie Anm. 27) S. 554, FHA, Bd. 19 (wie Anm. 26) S. 100; vgl. auch Volker Schäfer, Das Stammbuch des Tübinger Stiftlers August Faber mit seinem Hölderlineintrag von 1789, in: Tubingensia. Impulse zur Stadt- und Universitätsgeschichte. Festschrift Wilfried Setzler, hg. von Sönke LOREnz/Volker SCHÄFER, Ostfildern 2008, S. 397-426.

48 Vgl. Stb. Buttersack (150 Bl., 1787-1791), WLB Cod.hist.oct.278, Bl.7v; Schäfer, Neue Stammbuchblätter 2005 (wie Anm.1) S.312f.; vgl. auch Kunn, Schwarzbrot (wie Anm. 8) S. 29, 62; Kunn/Schweigard (wie Anm. 8) S. 138. Nur in Abschrift überliefert ist Hegels Freundschaftswidmung vom 16. September 1789 für Johann Eberhard Schwarz (1773-1838) von Stuttgart, Pfarrer in Löchgau. Vgl. SсH Ä FER, Ein unbekanntes Stammbuchblatt (wie Anm. 28).

${ }_{49}$ Gedichte von Carl Philipp Conz. Erste Sammlung, Tübingen 1792 (online gestellt), Subskribentenverzeichnis unter „Altensteig“: „Herr Dobel, Med.[icinae] D.[octor]“.

${ }^{50}$ Eintrag, datiert Tübingen 10. April 1791, Stb. Dobel Nr.198; Stb. Schmoller (wie Anm. 69) Bl. 4 mit Silhouette; Stb. Stahl (wie Anm. 14) Bl. 25 mit Silhouette; Ku Hn, Schwarzbrot (wie Anm. 8) S.26f., 44; Kuhn/Schweigard (wie Anm. 8) S. 122 f., 136f., 143, 217 f., 265; Wandel (wie Anm. 40) S. 39, 45, 56, 72, 159-151, Silhouette XIX Tafel 10; vgl. auch Anm. 13.

${ }^{51}$ Dazu gehören neben Hegel und Hölderlin, Fallot (wie Anm.38), Fink (wie Anm. 18) und Ferdinand Christian Harpprecht (1770-1839, Pfarrer, Stb. Dobel Nr. 172; Stb. Hegel (wie Anm. 38) Bl.25, Nicolin (wie Anm.18) S. 156), die in der revolutionären Studentenbewe- 
Freundeskreis von 20 bis 30 Personen rechnen dürfen. Von den gemeinsamen Freunden Hölderlins, Hegels und Dobels sind noch zu nennen Christian Ludwig Bilfinger (1770-1850) ${ }^{52}$, Jakob Friedrich Märklin (1771-1841) ${ }^{53}$, schon ein Schulfreund Hegels, der Mediziner Friedrich August Memminger (1769-1841), mit dem Hölderlin und Hiller in der Ostervakanz 1791 eine Fußreise in die republikanische Schweiz unternahmen ${ }^{54}$, Christian Ludwig Neuffer (1769-1839), Hölderlins engster Studienfreund, der mit ihm und Magenau im März 1790 den „Aldermannsbund“ gründete ${ }^{55}$, sowie der Primus von Hölderlins Promotion Carl Christoph Renz (1770-1829), mit dem sie Platon und Kant lasen ${ }^{56}$. Des weiteren bekundeten

gung noch eine Rolle spielen sollten, Kind (wie Anm. 19), Rößlin (wie Anm. 55) sowie die Hölderlinfreunde C.C.F. Bilfinger (wie Anm.39), C.C. Camerer (wie Anm. 43), Lang (wie Anm. 39) und Neuffer (wie Anm. 55). Breitschwerdt und Duttenhofer (wie Anm. 45), Knittel (wie Anm. 76), Mögling (wie Anm. 78) und Ostertag (wie Anm. 60) gehören ebenfalls zu den Subskribenten. Zur Studentenbewegung vgl. Kunn, Schwarzbrot (wie Anm. 8) S. 26-52, 57 f.; Kuhn/Schweigard (wie Anm. 8) S. 131-153, 272-285; Wandel (wie Anm. 40) S. 47-68.

${ }^{52}$ Stb. Dobel Nr. 4 (Text wie Reyscher Anm. 37); Stb. Hegel (wie Anm. 38) Bl. 5; Stb. Hiller (wie Anm. 40) Bl.29v; Bilfinger war Hölderlins Denkendorfer „Herzensfreund“. Vgl. „An M[einen] B [ilfinger]“, FHA, Bd. 1 (wie Anm. 27) S. 253-255; vgl. auch ebd., S. 299-302; vgl. Anm. 8, 39 .

53 Stb. Dobel Nr.134 aus Schillers Gedicht „Resignation“ (wie Anm.27): Zwo Blumen blühen für den weisen Finder. Sie heißen Hofnung und-Genuß. Wer dieser Blumen Eine brach, begehre die andre Schwester nicht; Genieße, wer nicht glauben kann, - wer glauben kann, - entbehre. Genieße und sey glïklich! (15. September 1790); Stb. Hegel (wie Anm. 38) Bl. 40; Nicolin (wie Anm.18) S.137; Stb. Faber (wie Anm. 47) Bl.65v; Stb. Süskind (wie Anm. 22) Bl.11v; Stb. Weigelin (wie Anm. 42) Bl.25; Fragmente seines Stammbuchs WLB Cod.hist.qt.612; vgl. Raberg (wie Anm. 43) S. 532f.; vgl. auch Anm. 26, 27.

${ }^{54}$ Stb. Dobel Nr. 38: Vertilge, verjage die quälenden Sorgen, sei lustig am Abend, sei lustig am Morgen. Ergöze dich öfters, doch trenne dich nicht, von Liebe, von Freundschaft, von nöthiger Pflicht. (24. Januar 1790) „Bruder“ (vgl. Anm. 8); Stb. Hiller (wie Anm. 40) Bl. 107v; Stb. A.E. Camerer (wie Anm. 69) Bl.98; ehemals Stb. Rueff (wie Anm. 41) mit Silhouette (vgl. Ulrich Häussermann, Hölderlin mit Selbstzeugnissen und Bilddokumenten, Hamburg 1990, S. 64, 185); Stb. Schmoller (wie Anm. 69) Bl. 166.

${ }_{55}$ Stb. Dobel Nr. 151: Der ist Weise, wer im Gleise immer neuer Frenden bleibt. Bald mit Freunden, bald beim Weine, bald in Amors Schattenhaine glüklich sich die Zeit vertreibt. (Mai 1790); vgl. Anm. 26, 51; „An Neuffer. Im Merz 1794“, FHA, Bd. 2 (wie Anm. 26) S. 207209; „Einladung an Neuffer“, FHA, Bd. 3 (wie Anm. 26) S. 11-20; Stb. Hegel (wie Anm. 38) Bl. 47, Nicolin (wie Anm. 18) S. 137; Stb. Buttersack (wie Anm. 48) Bl.64; Stb. Hiller (wie Anm. 40) Bl. 65 mit Silhouette; Stb. Rueff (wie Anm. 41); Stb. Schwarz (Schäfer, Ein unbekanntes Stammbuchblatt (wie Anm. 28) S. 261); Stb. Süskind (wie Anm. 22) Bl. 22v; Stb. Weigelin (wie Anm. 42) Bl.38; Biografisches Lexikon für Ulm und Neu-Ulm, bearb. von Frank Raberg, Ulm 2010, S. 292 f. Auch Christoph Heinrich Rößlin (1767-1831), zuletzt Pfarrer in Bermaringen, der 1804 Lore Hafner, eine Liebschaft Neuffers heiratete, zählt zu den Freunden Dobels (Stb. Dobel Nr.79; Stb. Hegel (wie Anm.38) Bl.51, Nicolin (wie Anm. 18) S. 152; Hayden-Roy (wie Anm. 7) S. 126-132, 224, 326, 344).

56 Vgl. Anm. 39; Stb. Faber (wie Anm. 47) Bl.57v; Stb. Hiller (wie Anm. 40) Bl. 67 mit Silhouette; Hölderlin zum 200. Geburtstag. Sonderausstellung des Schiller-Nationalmuseums, Katalog Nr.21, bearb. von Werner Volke, München 1970, S. 115; vgl. auch „... im Reiche des Wissens cavalieremente“? Hölderlins, Hegels und Schellings Philosophiestudium an 
in Dobels Album ihre Freundschaft Philipp Jakob Hiemer (1770-1814), Bruder des Hölderlin-Porträtisten ${ }^{57}$, Christian Philipp Friedrich Leutwein (1768-1838), von dem eine Charakteristik seines Stubengenossen Hegel überliefert ist ${ }^{58}$, Christian Immanuel Le Bret (1770-1843) und Ernst Carl Wilhelm Le Bret (geb. 1773), Brüder von Hölderlins Schwarm „Lyda“, Elise Le Bret $(1774-1839)^{59}$, ihr späterer Ehemann Wilhelm Friedrich Ostertag (1768-1845) ${ }^{60}$ und der bereits erwähnte nachmalige Schwager Carl Ludwig Reyscher ${ }^{61}$.

der Universität Tübingen, hg. von Michael Franz (Schriften der Hölderlin-Gesellschaft, Bd.23,2), Tübingen 2005; Ders., Tübinger Platonismus. Die gemeinsamen philosophischen Anfangsgründe von Hölderlin, Schelling und Hegel, Tübingen 2012; KunN, Schwarzbrot (wie Anm. 8) S.48, 56-58, 60; Kuhn/Schweigard (wie Anm. 8) S.149, 271f., 276, 278; WANDEL (wie Anm. 40) S. 39, 42, 53, 82.

57 Stb. Dobel Nr. 182 nach Philipper 1,21: Sterben ist dein Gewinn! (18. September 1790); Stb. Faber (wie Anm. 47) Bl.116v; Stb. Helfferich (wie Anm.19) Bl.6; Stb. Hiller (wie Anm. 40) Bl. 116 mit Silhouette; Stb. Merian (wie Anm. 46) Bl. 58; Stb. Süskind (wie Anm. 22) Bl. 10v; Stb. Weigelin (wie Anm. 42) Bl. 64; Bruder von Franz Carl Hiemer (1768-1822), der 1792 das bekannte Hölderlin-Porträt schuf, Stb. Hegel (wie Anm. 38) Bl. 23a, Nicolin (wie Anm. 18) S. 157; vgl. auch Kuhn (wie Anm. 8) S. 48, 51, 57; Kuhn/Schweigard (wie Anm. 8) S. 118 f.,149, 151 f., $272,276$.

58 Stb. Dobel Nr.36 mit Zitat von Gotthold Ephraim Lessing: Ein Kirchhof ist, mein frommer Christ, diß Büchelein, wo bald kann seyn dein Leichenstein ein Kreuzelein (16. September 1790). Stb. Faber (wie Anm. 47) Bl.60; Stb. Hegel (wie Anm. 38) Bl.39, Nicolin (wie Anm. 18) S. 155; vgl. auch Dieter Henrich, Leutwein über Hegel. Ein Dokument zu Hegels Biographie (Hegel-Studien, Bd.3), Bonn 1965, S.39-77; KuHN, Schwarzbrot (wie Anm. 8) S. 13-18, 36f.; Kuhn/Schweigard (wie Anm. 8) S. 144f., 274f.; Schöllkopf (wie Anm. 21) S. 96, 99.

59 Stb. Dobel Nr.141; Stb. Buttersack (wie Anm. 48) Bl.91; Stb. C.C.Camerer (wie Anm. 43) Bl. 80; Stb. Merian (wie Anm. 46) Bl. 65; Grab Hoppenlaufriedhof Stuttgart, Abt. 5b, Nr. 985; Stb. Dobel Nr. 166 (vgl. Anm. 8). Bei der benachbarten Einträgerin Nr. 164 „Friederike L.“ könnte es sich um deren Schwester Christiane Friederike Le Bret (17771837) nachmals verehelichte Eisenlohr handeln. Vgl. auch HAyden-Roy (wie Anm. 7) S. 241254. Unter dem Vorsitz ihres Vaters, des Theologieprofessors und Universitätskanzlers Johann Friedrich Le Bret (1732-1807), absolvierte Dobels Bruder Johann Friedrich im Juni 1788 seine theologische Abschlussdissertation - wie Hölderlin und Hegel fünf Jahre später. Vgl. Johann Friedrich LE BRET (Praes.), De suspectis religionem Christianam commendandi modis, Tübingen 1788; Ders., De Ecclesiae Wirtembergicae Renascentis Calamitatibus, Tübingen 1793; vgl. auch: „... an der Galeere der Theologie“? Hölderlins, Hegels und Schellings Theologiestudium an der Universität Tübingen, hg. von Michael Franz (Schriften der Hölderlin-Gesellschaft, Bd. 23,3), Tübingen 2007.

60 Stb. Dobel Nr. 185: Lectüre ist die Nabrung, Umgang die Übung, und Beobachtung die Medicin unsers Verstandes. (17. September 1790); Stb. Buttersack (wie Anm. 48) Bl. 67; Stb. Rueff (wie Anm. 41) Bl. 103 mit ganzfiguriger Silhouette in kolorierter Landschaft; Stb. Weigelin (wie Anm. 42) Bl. 62; Anm. 51. Die Eheschließung erfolgte 1799. Die Tochter Karoline Auguste (1808-1880) heiratete 1825 den Oberregierungsrat Johannes Schlayer (1792-1860), der es bis zum württembergischen Innenminister brachte. Vgl. HAYDEN-Roy (wie Anm.7) S. 264 f.; RABERG (wie Anm. 43) S. $787 \mathrm{f}$.

${ }^{61}$ Wie Anm. 37; Stb. Faber (wie Anm. 47) Bl. 26; Stb. Hegel (wie Anm. 38) Bl. 49, Nicolin (wie Anm. 18) S. 137; Stb. Weigelin (wie Anm. 42) Bl. 22.

Zeitschrift für Württembergische Landesgeschichte 74 (2015), S. 99-119.

(C) Kommission für geschichtliche Landeskunde in Baden-Württemberg und Württembergischer Geschichts- und Altertumsverein e.V.

ISSN 0044-3786 
Besonders gute Beziehungen scheint Christian Dobel zu den Familien Camerer und Märklin gehabt zu haben. In seinem Stammbuch begegnen - neben dem mehrfach genannten Reutlinger Pfarrerssohn Clemens Christoph Camerer ${ }^{62}$ - der Stiftler Philipp Gottfried Camerer (1767-1835), ein Freund Hegels ${ }^{63}$, und sein jüngerer Bruder, der Medizinstudent Johann Caspar Camerer, in dessen Freundschaftsalbum sich Hölderlin 1795 in Jena mit einem Text von Pascal eintrug ${ }^{64}$, Söhne des ebenfalls vertretenen Gottfried Wilhelm Camerer (1738-1805), Pfarrers von Sondelfingen ${ }^{65}$, einer Nachbargemeinde von Rommelsbach, sowie deren Vettern Christoph Ludwig Camerer (1768-1794), Stiftler, Pfarrerssohn von Dusslingen ${ }^{66}$, und Albrecht Ernst Camerer (1768-1792), Jurastudent von Öttingen ${ }^{67}$. In das Stammbuch seines Kommilitonen Johann Caspar Camerer schrieb Dobel in Rommelsbach am 6. April 1790: Die Welt ist ein Schauplaz, Du kommst-siebst-und gehst vorüber ${ }^{68}$ (Abb. 6) und in das von Albrecht Ernst Camerer ein Jahr darauf: Aus Handlungen, nicht aus Worten, kennt man die Menschen ${ }^{69}$. Auch zur Familie

62 Vgl. Anm. 35, 43, 51. Stb. A.E. Camerer (wie Anm. 69) Bl. 31; Stb. J. C. Camerer (wie Anm. 44) Bl. 28; Stb. Rueff (wie Anm. 41) Bl. 52 mit Silhouette; Stb. Schmoller (wie Anm. 69) Bl. 17.

63 Stb. Dobel Nr. 159 mit Zitat Jesus Sirach 38,3; Stb. Hegel (wie Anm. 38) Bl. 9, Nicolin (wie Anm. 18) S. 138; Stb. C.C. Camerer (wie Anm. 43) Bl.6; Stb. Weigelin (wie Anm. 42) Bl. 8. Philipp Gottfried Camerer gehörte mit Kind (wie Anm. 19), Magenau (wie Anm. 45) und Rößlin (wie Anm. 55) der Maulbronner Promotion vor Hölderlin an (MUT, Nr. 38490). Vgl. Hayden-Roy (wie Anm. 7) S. 167, Anm. 13, S. 324-326.

64 Wie Anm. 44; Stb. Dobel Nr. 92 nach Ovid: Non est in medico semper, relevetur ut aeger. Semper at in medico, ne relevetur, erit; Stb. A.E. Camerer (wie Anm. 69) Bl. 79; Stb. Weigelin (wie Anm. 42) Bl. 86; vgl. auch Anm. 68. Johann Caspar Camerer wirkte später als Oberamtsarzt in Blaubeuren.

65 Stb. Dobel Nr. 146: Memento Mori.

66 Stb. Dobel Nr. 8; MUT, Nr. 38389; Faber (wie Anm. 4) XXV, SS 115, 192 f., 313, 316, 478,480 .

${ }^{67}$ Stb. Dobel Nr. 152 nach Johann Gottfried Herder: Sterbliche sind wir und sterblich sind all unsere Wünsche: Leid und Freude, sie gehen oder wir gehen vorbei. (8. September 1790) „Bruder“ (wie Anm. 8); vgl. Anm. 13, 69; Stb. C.C. Camerer (wie Anm. 43) Bl. 31 „Bruder und Vetter", verso Heinrike Hölderlin (wie Anm. 43); Stb. J. C. Camerer (wie Anm. 44) Bl. 41 „Freund und Vetter“; Stb. Schmoller (wie Anm. 69) Bl. 155.

68 Wie Anm. 44, vgl. auch Anm. 64. Vgl. Matthias Claudius, Denksprüche alter Weisen, mit meinen Randglossen, in: Sämmtliche Werke des Wandsbecker Bothen. Erster und Zweyter Theil, Wandsbeck 1774, S. 111. Die zugehörige Randglosse lautet: „Und wirst vom Schauplatz vergessen, wer du auch seyst. Mach’ aber, daß dich das wenig kümmern dürfe.“

69 Stb. A.E. Camerer (178 Bl., 1789-1791), WLB Cod.hist.oct.234, Bl. 133; dieselbe Sentenz im Stb. Dobel Nr. 103 (Carl Hube, Medizinstudent aus Warschau, datiert Tübingen, 8. Dezember 1789). Das Stammbuch von A.E. Camerer hat mit dem Dobels 36 Freunde gemein. Vgl. auch Kuhn, Schwarzbrot (wie Anm. 8) S. 21, 29, 62; Kuhn/Schweigard (wie Anm. 8) S. 130, 138; Anm. 13, 67. Eine weitere Freundschaftswidmung Dobels, datiert H...g [Hornberg?] im Jun. [ius] 1791, ist im Stammbuch von Johann Christian Eberhard Schmoller (1769-1848) überliefert, seit 1818 Pfarrer in Rotfelden bei Nagold: Darum genieße Freund! Dein Leben, als müßest Morgen schon weggeben - Und Schone es, als ob ewig Du weiletest bier!! Dem Text nach Herder, den ihm Johann Philipp Weigelin (wie Anm. 20, 42) am 17. 


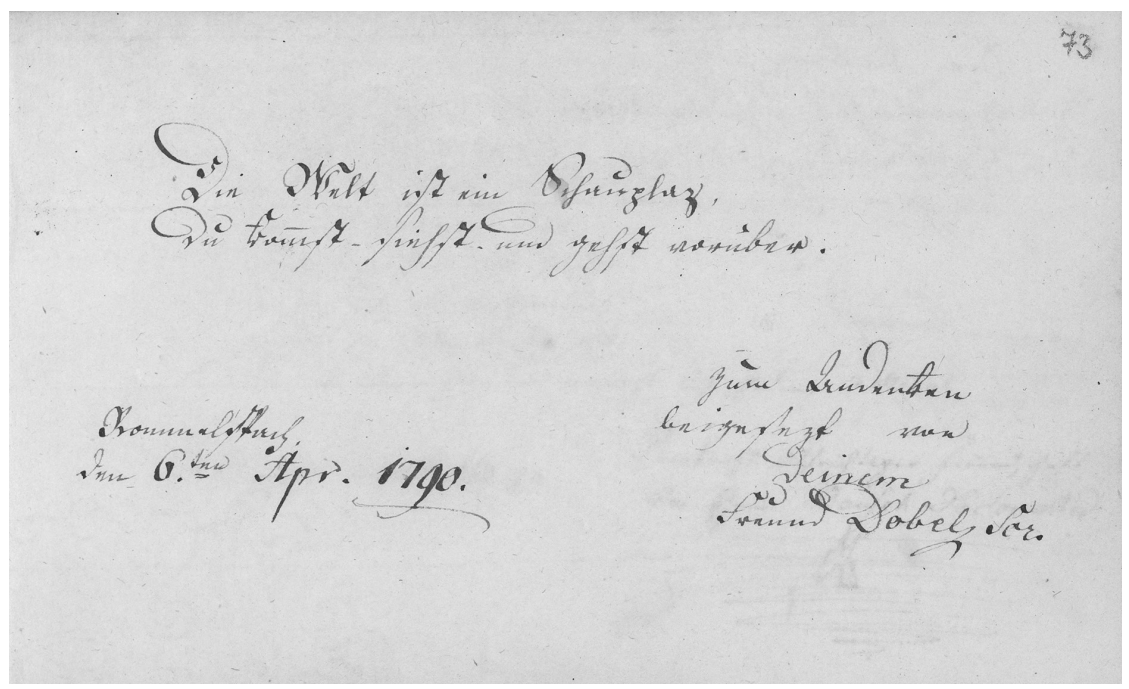

Abb. 6

Märklin hatte Christian Dobel mancherlei Kontakte. Nicht allein der Hölderlinfreund Jakob Friedrich Märklin dokumentierte seine Freundschaft in Dobels Album, sondern auch dessen Mutter Friederike geb. Rapp (1743-1804) ${ }^{70}$ sowie fast die gesamte Familie seiner Tante Dorothea Gottliebin Märklin geb. Hiller (17481802) ${ }^{71}$, Gattin des Tübinger Stadtdekans und Professors der Theologie Johann

März 1790 ins Stammbuch geschrieben hatte, fügt er noch hinzu: So lange wir nur noch den 6ten Theil eines Kreuzers in Compagnie fübren, gebt uns Freude und Vergnügen nicht aus!! Stb. Schmoller (224 Bl., 1786-1794, Privatbesitz, Kopie Universitätsarchiv Tübingen S 128/10) Bl.180; Stb. Dobel Nr.64; vgl. Volker SCHÄFER, Silhouetten aus dem Stammbuch des Tübinger Theologiestudenten Johann Christian Eberhard Schmoller, in: Bausteine (wie Anm. 8) Bd. 5, 1991, S. 85-98; KunN, Schwarzbrot (wie Anm. 8) S. 28f., 62; KunN/SCHweIGARD (wie Anm. 8) S. 138. Die Stammbücher Schmoller und Dobel weisen 38 identische Einträger auf.

70 Vgl. Anm. 27, 53; Faber (wie Anm. 4) III $\$ 758$.

71 Stb. Dobel Nr. 142: Währe die Sünde nicht in die Welt gekommen, so bedürfften wir deß Arzts nicht. Die Einträge der Schwägerinnen datieren beide Tübingen, 24. September 1790. Vertreten sind die Töchter Johanna Christiane Neundorf geb. Märklin (1769-1846) mit ihrem Gatten Carl Gottlieb Neundorf (1753-1814), Rechtskonsulent in Esslingen (Stb. Dobel Nr.130, 131); Elisabetha Dorothea Märklin (1771-1827), später verehelichte Faulhaber in Esslingen (Stb. Dobel Nr.129); Dorothea Gottliebin Märklin (1773-1856; Stb. Dobel Nr. 128), die 1793 Christoph Gottfried Bardili (1761-1808) ehelichte, Neffe von Nathanael Köstlin (vgl. Anm. 5, 23) und seit 1790 Professor für Philosophie an der Hohen Karlsschule - er wirkte auf seinen Cousin Schelling wie auf Hegel - und Johanne Märklin: Nur Seelen Rub ist Glük - ein frohes Herz ist himmlischer Gewinn (November 1789), Stb. Dobel Nr. 132 mit sekundär aufgeklebter getuschter Silhouette (vgl. Anm. 46); Faber (wie Anm. 70) \$757. 
Friedrich Märklin (1734-1804), seit 1792 Propst in Denkendorf. Zudem trug sich noch ein gemeinsamer Vetter ein, Ernst Friedrich Märklin (1771-1834) von Hohentwiel, Jakobiner, der als Oberamtsrichter in Urach den Hilfsschreiber Wilhelm Waiblinger (1804-1830) förderte ${ }^{72}$.

An weiteren in Dobels Stammbuch vertretenen Persönlichkeiten sind noch zu erwähnen der als Dekan in Reutlingen verstorbene David Friedrich Cless (17681810) ${ }^{73}$, Georg August Griesinger (1769-1845), Sächsischer Geheimer Legationsrat, Geschäftsträger und Agent für den Musikverlag Breitkopf \& Härtel in Wien, Freund und Biograph des Komponisten Joseph Haydn ${ }^{74}$, Justin Heinrich von Hillern (1771-1851) aus Biberach/Riß und mit Wieland verwandt, Direktor des Generallandesarchivs in Karlsruhe ${ }^{75}$, Gottlieb August Knittel (1768-1820), Stadtdekan

72 Stb. Dobel Nr. 31: Certus amicus in re incerta cernitur, Ennius auch Cicero zugeschrieben. Bemerkenswert ist, dass der Eintrag am 28. September 1790 in Tübingen erfolgte, zwei Jahre vor Märklins Immatrikulation (MUT, Nr. 38945). FAber (wie Anm. 70) \$759; Stb. Faber (wie Anm. 47) Bl. 84 mit Ordenskürzel und gekreuzten Säbeln. In das Stammbuch Hillers schrieb Ernst Märklin im Februar 1794 ein Zitat von St. Just mit dem Zusatz: denke jezuweilen auch noch an den 14. Juli 1793. an dein Gartten-Häuschen, und an---(Stb. Hiller (wie Anm. 40) Bl. 127 mit Silhouette, nach Hegel). Ein Eintrag, der in Hinsicht auf den umstrittenen Tanz um den Tübinger Freiheitsbaum das Interesse der Forschung auf sich zog. Vgl. Adolf Веск, Der Tübinger Freiheitsbaum 1793. Eine Legende, in: Schwäbische Heimat 29. Jg. Heft 3 (1978) S. 152-158; Kunn, Schwarzbrot (wie Anm. 8) S. 16-19; Kunn/SchweIGARD (wie Anm. 8) S. 149, 273-276, 279-281, 283, 410; Schöllkopf (wie Anm. 21) S. 97-102; WANDEL (wie Anm. 40) S. 52, 60f., 86; Wilhelm Waiblinger. Werke und Briefe, hg. von Hans KöNiger, Bd. 5,2: Sämtliche Briefe. Textkritik und Kommentar. Lebenschronik, Stuttgart 1985 (Veröffentlichungen der Deutschen Schillergesellschaft, Bd. 39), S. 620-623. In diesem Zusammenhang ist ein weiterer Freund Dobels zu nennen, der Stiftler Johann Jakob Griesinger (1772-1831) von der Solitude, gestorben als Pfarrer in Gültstein (Stb. Dobel Nr. 56). Er war mit Hegel Mitglied eines politischen Klubs sowie des „Unsinnscollegiums“. Isaak von Sinclair (1775-1815) bezeichnete ihn als „eifrigsten Patrioten“, der die Marseillaise übersetzt habe. Vgl. Stb. Hegel (wie Anm. 38) Bl.23, Nicolin (wie Anm. 18) S. 156; Kunn, Schwarzbrot (wie Anm. 8) S. 19, 38 f., 48, 51 f., 56f., 59; Kunn/Schweigard (wie Anm. 8) S. 146, 148, $151 \mathrm{f} ., 271 \mathrm{f} ., 277$; WANDEL (wie Anm. 40) S. 57, 60, Silhouette XVII, Tafel 5.

${ }^{73}$ Verfasser des Standartwerks „Versuch einer kirchlich-politischen Landes-und Cultur-Geschichte von Würtenberg bis zur Reformation“, drei Bände, Tübingen 1806 bis 1808; Stb. Dobel Nr. 119; Stb. C. C. Camerer (wie Anm. 43) Bl. 38v; Stb. Rueff (wie Anm. 41) Bl. 57; Stb. Schmoller (wie Anm. 69) Bl. 91 mit Silhouette; ADB, Bd. 4, Leipzig 1876, S. 329.

${ }^{74}$ Stb. Dobel Nr. 49: Wie seelig ists, ein Mensch zu seyn und Freundschafft zu genießen. (22. September 1790); Stb. C.C. Camerer (wie Anm.43) Bl.7; Stb. Hegel (wie Anm. 38) Bl.22, Nicolin (wie Anm.18) S.161; Stb. Rueff (wie Anm.41) Bl. 58 mit Silhouette; Stb. Schwarz (SCHäFer, Ein unbekanntes Stammbuchblatt (wie Anm. 28) S. 261); Stb. Weigelin (wie Anm. 42) Bl. 30; Ders., Biographische Notizen über Joseph Haydn, Leipzig 1810 (zahlreiche Nachdrucke); „Eben komme ich von Haydn ...“. Georg August Griesingers Korrespondenz mit Joseph Haydns Verleger Breitkopf und Härtel 1799-1819, hg. von Otto BıвA, Zürich 1987; Hayden-Roy (wie Anm. 7) S. 324, 345.

75 Stb. Dobel Nr. 20: Unser Leben ist ein Traum flüchtiger Gefüble. Aus gelanfen sind wir kaum stehen wir schon am Ziele. (Mai 1790) „Bruder“ (wie Anm. 8); Stb. A.E. Camerer (wie Anm. 69) Bl. 178; Badische Biographien, Bd. 1, Heidelberg 1875, S. 370 f.

Zeitschrift für Württembergische Landesgeschichte 74 (2015), S. 99-119.

(C) Kommission für geschichtliche Landeskunde in Baden-Württemberg und Württembergischer

Geschichts- und Altertumsverein e.V.

ISSN 0044-3786 
und Kirchenrat in Karlsruhe ${ }^{76}$, Friedrich Uffo Dieterich Lentz (1769-1854), Herzoglich-Oldenburgischer Geheimer Staatsrat ${ }^{77}$, Vertrauter des Prinzregenten Peter (1755-1823) - er begleitete ihn 1811 ins russische Exil -, Heinrich Friedrich Wolfgang Mögling (1771-1813), Direktor der Hof- und Domänenkammer, der dritte Ehrenbürger Stuttgarts ${ }^{78}$, und Dr. iur. Elias Gottfried Steeb (1767-1808), Karlsschüler, Professor in Tübingen, Deputierter und Mitglied des engeren Ausschusses im Stuttgarter Landtag, dessen Organ „Der Landtag im Herzogthum Wirtemberg" er von 1797 bis 1799 herausgab".

Wer so ein beachtliches Freundschaftsalbum hinterläßt wie Christian Amandus Heinrich Dobel, muss ein sympathischer Zeitgenosse gewesen $\operatorname{sein}^{80}$. Durch seinen frühen Tod bald in Vergessenheit geraten ist es nun dieses Stammbuch, das ihn nach über 200 Jahren als Freund Hölderlins und Hegels wieder in das Gedächtnis der Nachwelt ruft.

${ }^{76}$ Erster Pfarrer an der von Weinbrenner neu erbauten Evangelischen Stadtkirche (Gedenktafel in der Krypta); Stb. Dobel Nr. 156; Stb. J. C. Camerer (wie Anm. 44) Bl. 56v; Stb. Rueff (wie Anm. 41) Bl. 88; Stb. Weigelin (wie Anm. 42) Bl.46; Hayden-Roy (wie Anm. 7) S. 29,330 .

77 Stb. Dobel Nr. 104: Nicht ganz zum Glïk nicht ganz zum Leid ist uns diese Welt bestimmt. (Oktober 1790). Lentz, der erst im Oktober 1790 zum Jurastudium von Erlangen nach Tübingen gekommen war, unternahm im Frühjahr 1791 eine (konspirative?) Reise nach Straßburg. Mit ihm starb der letzte studentische Einträger. Vgl. Wandel (wie Anm. 40) S. 55; Biographisches Lexikon zur Geschichte des Landes Oldenburg, hg. von Hans FriedL, Oldenburg 1992, S. 417.

78 Geheimer Legationsrat, Vizedirektor der Porzellankommission (Ludwigsburg), Adelsstand 1811; Stb. Dobel Nr.167; Stb. Faber (wie Anm. 47) Bl.55; Stb. Süskind (wie Anm. 22) Bl. 16; Grab Hoppenlaufriedhof, Abt. 3b, Nr. 469.

79 Stb. Dobel Nr.14: Drey und viermal glüklich ist, wen sein Mädchen feurig küßt. Schriebs Bruder Steeb von edlem Blut, der wenig hat und viel verthut. (2. Oktober 1790); Stb. Hiller (wie Anm.40) Bl. 215 mit Silhouette. Steeb heiratete 1796 Luise Heller (17681798) von Klosterreichenbach (Stb. Dobel Nr. 86) und beging als Oberamtmann von Calw auf der Flucht Suizid. Über seinen Bruder, den Tübinger Lammwirt Johann Heinrich Steeb (1750-1799), ist er ein Onkel des seligen Carlo Steeb (1773-1856). Im „Goldenen Lamm“ am Marktplatz verkehrte nachweislich auch Hölderlin. Vgl. Gebhardt (wie Anm.8) S.491; Walter Grube, Der Stuttgarter Landtag 1457-1957, Stuttgart 1957, S. 456-459, 466, 472-476, 478, 480; Rudolf Seigel, Die Ahnen des Karl Steeb, in: Tübinger Blätter 45 (1958) S. 24-29, hier S. 25; Wandel (wie Anm.40) S. 49, 86f., 140 f., 170 f., 175 f., Silhouette XX Tafel 12; BeCK (wie Anm. 1) S. 45; Anm. 43.

${ }^{80}$ Darauf weist auch die für damalige Verhältnisse bemerkenswerte Anzahl von 30 Frauen hin, die sich in Dobels Stammbuch als Freundinnen bezeichnen, wenn auch zum Teil diskret nur ihre Initialen hinterlassend. 